\title{
Parametric Resonance Characteristics of Laminated Composite Curved Shell Panels in a Hygrothermal Environment
}

\author{
S.K Sahu* and M.K.Rath** \\ Department of Civil Engineering, National Institute of Technology, Rourkela, India \\ P.K Datta*** \\ Department of Aerospace Engineering, Indian Institute of Technology, Kharagpur, India \\ R. Sahoo**** \\ Department of Civil Engineering, National Institute of Technology, Rourkela, India
}

\begin{abstract}
The present study deals with the parametric resonance behaviour of laminated composite curved shell panels in a hygrothermal environment using Bolotin's approach. A simple laminated model is developed using first order shear deformation theory (FSDT) for the vibration and dynamic stability analysis of laminated composite shells subjected to hygrothermal conditions. A computer program based on the finite element method (FEM) in a MATLAB environment is developed to perform all necessary computations. Quantitative results are presented to show the effects of curvature, ply-orientations, degree of orthotropy and geometry of laminates on the parametric instability of composite curved shell panels for different temperature and moisture concentrations. The excitation frequencies of laminated composite panels decrease with the increase of temperature and moisture due to reduction of stiffness for all laminates.
\end{abstract}

Key words: Parametric resonance; Excitation frequencies; Hygrothermal environment; Instability regions.

\section{Introduction}

Composite materials are being increasingly used in aerospace, civil, naval and other high-performance engineering applications due to their light weight, high specific strength, stiffness, excellent thermal characteristics, and ease in fabrication and other significant attributes. Structures used in the above fields are very often exposed to high temperatures as well as moisture. The varying environmental conditions due to moisture absorption and temperature seem to have an adverse effect on the stiffness and strength of the structural composites. This wide range of practical applications demands a fundamental understanding of their vibrations, static and dynamic stability characteristics under hygrothermal conditions. Thus the parametric resonance characteristics of laminated composite curved panels subjected to hygro-thermoelastic loads are of tremendous practical importance in the prediction of structures behavior under in-plane periodic loads.

The previous studies on vibration and buckling of composite panels subjected to hygrothermal loads are available in literature and reviewed by Tauchert [1] through 1991. The effects of hygrothermal conditions on the free vibration of laminated panels was considered earlier by Whitney and Ashton [2] using the Ritz method based on the classical laminated plate theory. Sai Ram and Sinha [3] and Patel et al. [4] presented the effects of moisture
This is an Open Access article distributed under the terms of the Creative Commons Attribution Non-Commercial License (http://creativecommons.org/licenses/by$\mathrm{nc} / 3.0 /$ ) which permits unrestricted non-commercial use, distribution, and reproduction in any medium, provided the original work is properly cited.

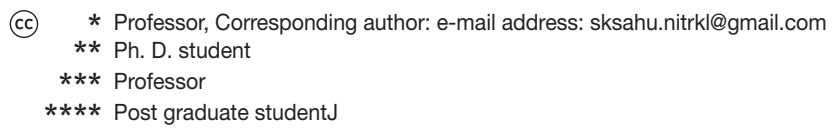


and temperature on the linear free vibration of laminated composite plates using first order and higher order shear deformation theories respectively. The vibration response of flat and curved panels subjected to thermal and mechanical loads are presented by Librescu and Lin [5]. Parhi et al.[6] investigated the effect of moisture and temperature on the dynamic behavior of composite plates and shells with or without delaminations. The dynamic analysis of laminated cross-ply composite non-circular thick cylindrical shells subjected to thermal/mechanical load based on higher order theory was studied by Ganapathi et al. [7]. Huang and Tauchert [8] investigated the large deformation behavior of anti-symmetric angle-ply curved panels under non-uniform temperature loading.

A geometrically nonlinear analysis of linear viscoelastic laminated composite systems subjected to a mechanical and hygrothermal load was presented by Marques and Creus [9] considering three-dimensional degenerated shell element. The nonlinear free vibration behavior of laminated composite shells subjected to a hygrothermal environment was investigated by Naidu and Sinha [10]. The geometrically non-linear vibrations of linear elastic composite laminated shallow shells under the simultaneous action of thermal fields and mechanical excitations are analysed by Ribeiro and Jansen [11]. The vibration characteristics of pre and post-buckled hygro-thermo-elastic laminated composite doubly curved shells was investigated by Kundu and Han [12]. Panda and Singh [13] studied the nonlinear free vibration behavior of single/doubly curved shell panels which addressed the post-buckled state where thermal post-buckling of shell panels was accounted for in a uniform temperature field. The finite element method was applied to study the problem of moisture and temperature effects on the stability of a general orthotropic cylindrical composite shell panels subjected to axial or in-plane shear loading by Lee and Yen [14]. The effect of hygrothermal conditions on the post buckling of shear deformable laminated cylindrical shells subjected to combined loading of axial compression and external pressure was investigated using a micro-to-macro mechanical analytical model by Shen [15]. Finally, the hygrothermoelastic buckling behaviour of laminated composite shells were numerically simulated using a geometrically nonlinear finite element method was studied by Kundu and Han [16]. The effect of random system properties on the post buckling load of geometrically nonlinear laminated composite cylindrical shell panels subjected to hygro-thermo-mechanical loading is investigated by Lal et al. [17].

The dynamic stability or, more particularly, the phenomenon of parametric resonance in cylindrical shells under periodic loads has attracted much attention due to its detrimental and de-stabilizing effects in many engineering applications. This phenomenon in elastic systems was first studied by Bolotin [18], where the dynamic instability regions were determined by a solution of the Mathieu-Hill equation. Based on Donnell's shell equations, the dynamic stability of circular cylindrical shells under both static and periodic compressive forces was examined by Nagai and Yamaki [19] using Hsu's method. Bert and Birman [20] extended the study of the parametric instability of thick orthotropic shells using higher-order theory. Liao and Cheng [21] proposed a finite element model with a 3-D degenerated shell element and a 3-D degenerated curved beam element to investigate the dynamic stability of stiffened isotropic and laminated composites plates and shells subjected to in-plane periodic forces. Argento and Scott [22] employed a perturbation technique to study the dynamic stability of layered anisotropic circular cylindrical shells under axial loading. The study of the parametric instability behavior of curved panels, the effects of curvature and aspect ratio on dynamic instability for a uniformly loaded laminated composite thick cylindrical panel was studied by Ganapathi et al. [23] using the finite element method. The parametric resonance characteristics of laminated composite doubly curved panels subjected to non-uniform loading was investigated by Sahu and Datta [24]. The dynamic stability of thin cross-ply laminated composite cylindrical shells is under combined static and periodic axial force is investigated by NG et al. [25] using Love's classical theory of thin shells. The dynamic stability behavior of laminated composite curved panels with cutouts subjected to in-plane static and periodic compressive loads was studied by Sahu and Dutta [26]. A numerical technique is developed for the dynamic stability analysis of composite laminated cylindrical shells under static and periodic axial forces by mesh-free kp-Ritz method by Liew et al. [27]. Sahu and Asha [28] also studied the parametric instability of angle ply curved panels with twist having turbo-machinery applications using the finite element method and Bolotin's approach.

However, all the above studies deal with the parametric resonance characteristics of composite shells without considering the hygrothermal effects. To the best of this author's knowledge, no study has reported on the dynamic instability of laminated composite panels under hygrothermal loads. In the present study, the parametric resonance characteristics of plates/cylindrical/doubly curved composite panels subjected to hygrothermal loading are investigated using the finite element method (FEM). Quantitative results are presented to show the effects of curvature, ply-orientation, and degree of orthotropy 
and geometry of laminate on parametric instability of composite panels for different temperature and moisture concentrations.

\section{Mathematical Formulations}

The mathematical formulations for parametric instability behavior of laminated composite panels due to in-plane periodic loading consideration in hygrothermal conditions are presented.

\subsection{The Basic Problems}

The basic configuration of the problem considered here is a doubly curved panel with in-plane loadings subjected to hygrothermal conditions as shown in Fig.1.

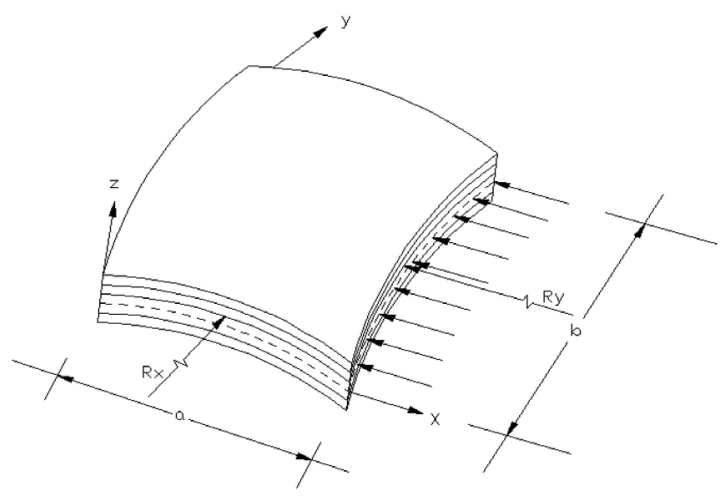

Fig. 1. Doubly curved panel under in-plane harmonic loading

The choice of the doubly curved panel geometry as a basic configuration has been made so that depending on the value of curvature parameter orplate, cylindrical panels and different doubly curved panels can be considered on a case by case basis. Consider a laminated panel of uniform thickness ' $t$ ', consisting of a number of thin laminate, each of which may be arbitrarily oriented at an angle ' $\theta$ ' with reference to the $\mathrm{X}$-axis of the co-ordinate system as shown in Figures 2 and 3.

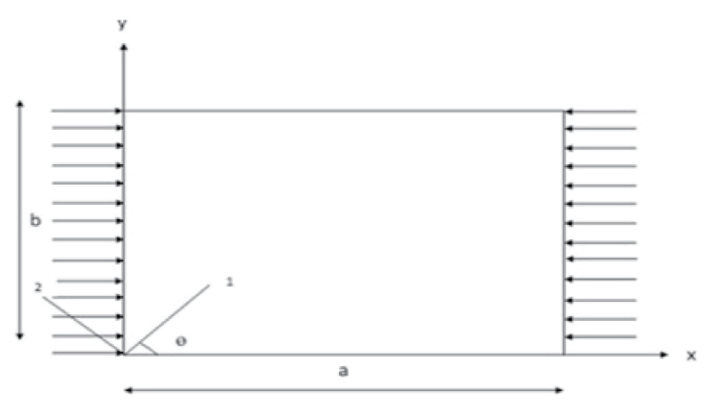

Fig. 2. Arbitary oriented laminated plate

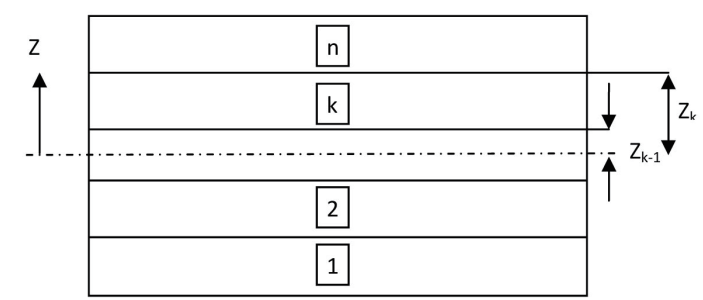

Fig. 3. Geometry of an N-layered laminate

\subsection{Proposed Analysis}

The governing equations for the dynamic stability of laminated composite doubly curved panels/shells subjected to hygrothermal loading are developed. The equation of motion represents a system of second order differential equations with periodic coefficients of the Mathieu-Hill type. The development of the regions of instability or dynamic instability regions (DIR) arises from Floquet's theory and the solution is obtained using Bolotin's approach using the finite element method (FEM). The governing differential equations have been developed using first order shear deformation theory(FSDT). The analysis is linear and the loading considered is axial with a simple harmonic fluctuation with respect to time. All damping effects are neglected.

\subsection{Governing Equations}

The governing differential equations for vibration of a shear deformable composite plates and shells in hygrothermal environments are derived on the basis of first order shear deformation theory subjected to in-plane loads:

$$
\begin{gathered}
\frac{\partial N_{x}}{\partial x}+\frac{\partial N_{x y}}{\partial y}+\frac{Q_{x}}{R_{x}}+\frac{Q_{y}}{R_{x y}}=P_{1} \frac{\partial^{2} u}{\partial t^{2}}+P_{2} \frac{\partial^{2} \theta_{x}}{\partial t^{2}} \\
\frac{\partial N_{x y}}{\partial x}+\frac{\partial N_{y}}{\partial y}+\frac{Q_{y}}{R_{y}}+\frac{Q_{x}}{R_{x y}}=P_{1} \frac{\partial^{2} v}{\partial t^{2}}+P_{2} \frac{\partial^{2} \theta_{y}}{\partial t^{2}} \\
\frac{\partial Q_{x}}{\partial x}+\frac{\partial Q_{y}}{\partial y}-\frac{N_{x}}{R_{x}}-\frac{N_{y}}{R_{y}}-2 \frac{N_{x y}}{R_{x y}}+N_{x}^{a} \frac{\partial^{2} w}{\partial x^{2}}+N_{y}^{a} \frac{\partial^{2} w}{\partial y^{2}}+N_{x y}^{a} \frac{\partial^{2} w}{\partial x \partial y}=P_{1} \frac{\partial^{2} w}{\partial t^{2}} \\
\frac{\partial M_{x}}{\partial x}+\frac{\partial M_{x y}}{\partial y}-Q_{x}=P_{3} \frac{\partial^{2} \theta_{x}}{\partial t^{2}}+P_{2} \frac{\partial^{2} u}{\partial t^{2}} \\
\frac{\partial M_{x y}}{\partial x}+\frac{\partial M_{y}}{\partial y}-Q_{y}=P_{3} \frac{\partial^{2} \theta_{y}}{\partial t^{2}}+P_{2} \frac{\partial^{2} v}{\partial t^{2}}
\end{gathered}
$$

Where $\mathrm{N}_{x}, \mathrm{~N}_{y}$ and $\mathrm{N}_{x y}$ denote the in-plane stress resultants, $\mathrm{M}_{x}, \mathrm{M}_{y}$ and $\mathrm{M}_{x y}$ are moment resultants and $\mathrm{Q}_{x}, \mathrm{Q}_{y}$ are transverse shear stress resultants. $\mathrm{N}_{x}{ }^{a}, \mathrm{~N}_{y}{ }^{a}$ and $\mathrm{N}_{x y}{ }^{a}$ are applied in - plane loads. $\mathrm{R}_{x}, \mathrm{R}_{y}$ and $\mathrm{R}_{x y}$ identify the radii of curvatures of the panel in the $x$ and $y$ axis and radius of twist. $\mathrm{u}, v$ and $w$ denote displacements along the $x, y$ and $z$ axes. $\theta x, \theta y$ are the 
rotations.

$$
\left(P_{1}, P_{2}, P_{3}\right)=\sum_{k=1}^{n} \int_{z_{k-1}}^{z_{k}}(\rho)_{k}\left(1, z, z^{2}\right) d z
$$

Where $\mathrm{n}=$ number of layers of laminated composite curved panel, $(\rho)_{k}=$ mass density of kth layer from mid-plane. $P_{1}, P_{2}$ and $P_{3}$ are the mass moment of inertias. $Z_{k}=$ distance of Kth layer from the reference plane.

\subsection{Dynamic Stability Studies}

Substituting the standard energy expressions which include strain energy due to bending and transverse shear, work done by external in-plane loads, residual stresses due to hygrothermal conditions and kinetic energy in Lagrange's equation and on simplifications, the equation of motion for vibration of a laminated composite panel in a hygrothermal environment, subjected to generalized in-plane load $N(t)$ may be expressed in the 'matrix' form as:

$$
[M]\{\ddot{q}\}+\left[[K]+\left[K_{g}^{r}\right]-N(t)\left[K_{g}\right]\right]\{q\}=0
$$

Where ' $\mathrm{q}$ ' is the vector of degrees of freedoms $(\mathrm{u}, \mathrm{v}, \mathrm{w}, \theta x$, $\theta y$ ). The in-plane load ' $N(t)$ ' may be harmonic and can be expressed in the form:

$$
N(t)=N_{s}+N_{t} \operatorname{Cos} \Omega t
$$

Where $N_{s}$ the static portion of load $N(t)$, the amplitude of the dynamic portion of $N(t)$ and $\Omega$ is the frequency of the excitation. The stress distribution in the panel may be periodic. Considering the static and dynamic component of load as a function of the critical load,

$$
N_{s}=\alpha N_{c r}, N_{t}=\beta N_{c r}
$$

Where $\alpha$ and $\beta$ are the static and dynamic load factors respectively. Using Eq. (5), the equation of motion for panel in hygrothermal environment under periodic loads in matrix form may be obtained as:

$$
[M]\{\ddot{q}\}+\left[[K]+\left[K^{r}{ }_{g}\right]-\alpha N_{c r}\left[K_{g}\right]-\beta N_{c r}\left[K_{g}\right] \operatorname{Cos} \Omega t\right]\{q\}=0
$$

The above Equation (6) represents a system of differential equations with periodic coefficients of the Mathieu-Hill type. The development of regions of instability arises from Floquet's theory which establishes the existence of periodic solutions of periods $\mathrm{T}$ and $2 \mathrm{~T}$. The boundaries of the primary instability regions with period $2 \mathrm{~T}$, where $\mathrm{T}=2 / \Omega$ are of practical importance and the solution can be achieved in the form of the trigonometric series:

$$
\begin{aligned}
& q(t)=\sum_{k=1,3,5, . .}^{\infty}\left[\left\{a_{k}\right\} \operatorname{Sin}(k \Omega t / 2)+\left\{b_{k}\right\} \operatorname{Cos}(k \Omega t / 2)\right] \\
& {[M] \sum_{K=1,3,5}^{\infty}-\left(\frac{K \Omega}{2}\right)^{2}\left(\left\{a_{K}\right\} \operatorname{Sin}\left(\frac{K \Omega t}{2}\right)+\left\{b_{K}\right\} \operatorname{Cos}\left(\frac{K \Omega t}{2}\right)\right)+\left[[K]+\left[K^{r}{ }_{g}\right]-\alpha P_{c r}\left[K_{g}\right]\right.} \\
& \left.-\beta P_{c r}\left[K_{g}\right] \operatorname{Cos} \Omega t\right]\left(\left\{a_{K}\right\} \operatorname{Sin}\left(\frac{k \Omega t}{2}\right)+\left\{b_{K}\right\}+\operatorname{Cos}\left(\frac{K \Omega t}{2}\right)\right)=0
\end{aligned}
$$

Equating the coefficients of the sine and cosine terms leads to a series of algebraic equations for the vectors $\{a\}_{K}$ and $\{b\}_{K}$ in the determination of instability regions. For a nontrival solution, the infinite determinants of the coefficients of the groups of homogeneous equations are equal to zero. Approximate solutions can be obtained by truncating the determinants. Principal instability regions, which are of practical interest corresponds to $\mathrm{K}=1$ and these instability conditions are in line with the Bolotin [18] but modified to consider hygrothermal loadings.

$$
\left[[K]+\left[K_{g}^{r}\right]-\alpha P_{c r}\left[K_{g}\right] \pm \frac{1}{2} \beta P_{c r}\left[K_{g}\right]-\frac{\Omega^{2}}{4}[M]\right]\{q\}=0
$$

Equation (9) represents an eigenvalue problem for known values of $\alpha, \beta$ and $P_{c r}$. The two conditions under the plus and minus sign correspond to two boundaries (upper and lower) of the dynamic instability region. The above eigenvalue solution applies s the value of $\Omega$, which gives the boundary frequencies of the instability regions for the given values of $\alpha$ and $\beta$. In this analysis, the computed static buckling load of the panel is considered as the reference load. Before solving the above equations, the stiffness matrix $[\mathrm{K}]$ is modified through imposition of boundary conditions. The equation reduces to other problems as follows:

Free Vibration: $\alpha=0, \beta=0$ and $\Omega=2 \omega$

$$
\left[[K]+\left[K_{g}^{r}\right]\right]-\omega_{n}{ }^{2} \quad[M]\{q\}=0
$$

Buckling: $\alpha=0, \beta=0$ and $\Omega=0$

$$
\left[[K]+\left[K^{r}{ }_{g}\right]\right]-\lambda\left[K_{g}\right]\{q\}=0
$$

\subsection{Finite Element Formulation}

An eight nodded iso-parametric element is used for static stability analysis of woven fiber composite plates subjected to a hygrothermal environment. Five degrees of freedom $u, v, w, \theta x$ and $\theta y$ are considered at each node. The element is modified to accommodate laminated materials and hygrothermal conditions of the panel, based on first 
order shear deformation theory where $u, v$ and $w$ are the displacement components in the $x, y, z$ axes and $\theta x$ and $\theta y$ are the rotations. The stiffness matrix, geometric stiffness matrix due to residual stresses, geometric stiffness matrix due to applied in-plane loads and nodal load vectors of the element are derived using the principle of minimum potential energy. The shape function of the element in Fig.4 are defined as [32].

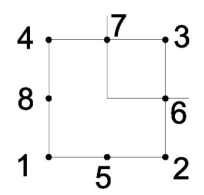

Fig. 4. Eight nodded isoparametric element

$$
\begin{array}{ll}
N_{i}=\frac{1}{4}\left(1+\xi \xi_{i}\right)\left(1+\eta \eta_{1}\right)\left(\xi \xi_{1}+\eta \eta_{1}-1\right) & \text { For } i=1,2,3 \text { and } 4 \\
N_{i}=\frac{1}{2}\left(1-\xi^{2}\right)\left(1+\eta \eta_{i}\right) & \text { For } i=5,7 \\
N_{i}=\frac{1}{2}\left(1-\xi \xi_{i}\right)\left(1-\eta^{2}\right) & \text { For } i=6,8
\end{array}
$$

\subsection{Constitutive Relations}

The constitutive relations for the plate and shell subjected to moisture and temperature is given by:

$$
\{F\}=[D]\{\varepsilon\}-\left\{F^{N}\right\}
$$

$F^{N}=$ Non mechanical forces due to temperature and moisture $[D]$ and $\{\boldsymbol{\varepsilon}\}$ are Elasticity and strain matrix respectively.

Where

$$
\begin{aligned}
& \{F\}=\left\{N_{x}, N_{y}, N_{x y}, M_{x}, M_{y}, M_{x y}, Q_{x}, Q_{y}\right\}^{T} \\
& \left\{F^{N}\right\}=\left\{N_{x}{ }^{N}, N_{y}{ }^{N}, N_{x y}, M_{x}{ }^{N}, M_{y}{ }^{N}, M_{x y}{ }^{N}, 0,0\right\}^{T} \\
& \{\varepsilon\}=\left\{\varepsilon_{x}, \varepsilon_{y}, \gamma_{x y}, K_{x}, K_{y}, K_{x y}, \varphi_{x}, \varphi_{y}\right\}^{T} \\
& {[D]=\left[\begin{array}{ccccccccc}
A_{11} & A_{12} & A_{16} & B_{11} & B_{12} & B_{16} & 0 & 0 \\
A_{12} & A_{22} & A_{26} & B_{12} & B_{22} & B_{26} & 0 & 0 \\
A_{16} & A_{26} & A_{66} & B_{16} & B_{26} & B_{66} & 0 & 0 \\
B_{11} & B_{12} & B_{16} & D_{11} & D_{12} & D_{16} & 0 & 0 \\
B_{12} & B_{22} & B_{26} & D_{12} & D_{22} & D_{26} & 0 & 0 \\
B_{16} & B_{26} & B_{66} & D_{16} & D_{26} & D_{66} & 0 & 0 \\
0 & 0 & 0 & 0 & 0 & 0 & S_{44} & S_{45} \\
0 & 0 & 0 & 0 & 0 & 0 & S_{45} & S_{55}
\end{array}\right]}
\end{aligned}
$$

The non-mechanical force and moment resultants due to moisture and temperature are expressed as follows:

$$
\begin{aligned}
& \left\{N_{x}{ }^{N}, N_{y}{ }^{N}, N_{x y}{ }^{N}\right\}^{T}=\sum_{K=1}^{n}\left(\overline{Q_{i j}}\right)\{\varepsilon\}_{k}\left(z_{k}-z_{k-1}\right) \quad \text { For } i, j=1,2,6 \\
& \left\{M_{x}{ }^{N}, M_{y}{ }^{N}, M_{x y}{ }^{N}\right\}^{T}=\frac{1}{2} \sum_{K=1}^{n}\left(\overline{Q_{i j}}\right)\{\varepsilon\}_{k}\left(z_{k}{ }^{2}-z_{k-1}{ }^{2}\right) \quad \text { For } \quad i, j=1,2,6
\end{aligned}
$$

Where

$$
\{\varepsilon\}_{N}=\left\{\varepsilon_{x N}, \varepsilon_{y N}, \varepsilon_{x y N}\right\}^{T}=[T]\left\{\beta_{1} \beta_{2}\right\}_{k}^{T}\left(C-C_{O}\right)+[T]\left\{\alpha_{1} \alpha_{2}\right\}_{k}^{T}\left(T-T_{O}\right)
$$

in which $[T]=$ Transformation matrix due to moisture and temperature and is given as

$$
[T]=\left[\begin{array}{cc}
\cos ^{2} \theta & \sin ^{2} \theta \\
\sin ^{2} \theta & \cos ^{2} \theta \\
\sin 2 \theta & \cos 2 \theta
\end{array}\right]
$$

The standard stiffness coefficients for laminated composites are considered in line with [26].

\subsection{Strain Displacement Relations}

Green-Lagrange's strain displacement relations are presented in general throughout the analysis. The linear part of the strain is used to derive the elastic stiffness matrix and the non-linear part of the strain is used to derive the geometric stiffness matrix. The total strain is given by:

$$
\{\varepsilon\}=\left\{\varepsilon^{l}\right\}+\left\{\varepsilon^{n l}\right\}
$$

The linear generalized shear deformable strain displacement relations are

$$
\begin{aligned}
& \varepsilon_{x}{ }^{l}=\frac{\partial u}{\partial x}+\frac{w}{R_{x}}+z k_{x} \\
& \varepsilon_{y}{ }^{l}=\frac{\partial v}{\partial y}+\frac{w}{R_{y}}+z k_{y} \\
& \gamma_{x y}{ }^{\prime}=\frac{\partial u}{\partial y}+\frac{\partial v}{\partial x}+\frac{2 w}{R_{x y}}+z k_{x y} \\
& \gamma_{x z}{ }^{\prime}=\frac{\partial w}{\partial x}+\theta_{x}-\frac{u}{R_{x}}-\frac{v}{R_{x y}} \\
& \gamma_{y z}{ }^{\prime}=\frac{\partial w}{\partial y}+\theta_{y}-\frac{v}{R_{y}}-\frac{u}{R_{x y}}
\end{aligned}
$$


The bending strains kj are expressed as:

$$
\begin{aligned}
& k_{x}=\frac{\partial \theta_{x}}{\partial x}, \quad \mathrm{k}_{\mathrm{y}}=\frac{\partial \theta_{y}}{\partial y} \\
& k_{x y}=\frac{\partial \theta_{x}}{\partial y}+\frac{\partial \theta_{y}}{\partial x}+\frac{1}{2}\left(\frac{1}{R_{y}}-\frac{1}{R_{x}}\right)\left(\frac{\partial v}{\partial x}-\frac{\partial u}{\partial y}\right)
\end{aligned}
$$

The non-linear strain components are as follows:

$\varepsilon_{\mathrm{xnl}}=\frac{1}{2}\left(\frac{\partial \mathrm{u}}{\partial \mathrm{x}}\right)^{2}+\frac{1}{2}\left(\frac{\partial \mathrm{v}}{\partial \mathrm{x}}\right)^{2}+\frac{1}{2}\left(\frac{\partial \mathrm{w}}{\partial \mathrm{x}}-\frac{\mathrm{u}}{\mathrm{R}_{\mathrm{x}}}\right)^{2}+\frac{1}{2} \mathrm{z}^{2}\left[\left(\frac{\partial \theta_{\mathrm{x}}}{\partial \mathrm{x}}\right)^{2}+\left(\frac{\partial \theta_{\mathrm{y}}}{\partial \mathrm{x}}\right)^{2}\right]$

$\varepsilon_{y n l}=\frac{1}{2}\left(\frac{\partial u}{\partial y}\right)^{2}+\frac{1}{2}\left(\frac{\partial v}{\partial y}\right)^{2}+\frac{1}{2}\left(\frac{\partial w}{\partial y}-\frac{v}{R_{y}}\right)^{2}+\frac{1}{2} z^{2}\left[\left(\frac{\partial \theta_{x}}{\partial y}\right)^{2}+\left(\frac{\partial \theta_{y}}{\partial y}\right)^{2}\right]$

$\gamma_{x x m l}=\frac{\partial u}{\partial x}\left(\frac{\partial u}{\partial y}\right)+\frac{\partial v}{\partial x}\left(\frac{\partial v}{\partial y}\right)+\left(\frac{\partial w}{\partial x}-\frac{u}{R_{x}}\right)\left(\frac{\partial w}{\partial y}-\frac{v}{R_{y}}\right)+z^{2}\left[\left(\frac{\partial \theta_{x}}{\partial x}\right)\left(\frac{\partial \theta_{x}}{\partial y}\right)+\left(\frac{\partial \theta_{y}}{\partial x}\right)\left(\frac{\partial \theta_{y}}{\partial y}\right)\right]$

\subsection{Element Elastic Stiffness Matrix}

The linear strain matrix $\{\boldsymbol{\varepsilon}\}$ is expressed as :

$$
\{\varepsilon\}=[B]\left\{\delta_{e}\right\}
$$

Where

$$
\left\{\delta_{e}\right\}=\left\{u_{1}, v_{1}, w, \theta_{x 1}, \theta_{y 1} \ldots \ldots \ldots, u_{8}, v_{8}, w_{8} \theta_{x 8}, \theta_{y 8}\right\}^{T}
$$

$$
[B]=\sum_{i=1}^{8}\left[\begin{array}{ccccc}
N_{i, x} & 0 & \frac{N_{i}}{R_{X}} & 0 & 0 \\
0 & N_{i, y} & \frac{N_{I}}{R_{y}} & 0 & 0 \\
N_{i, y} & N_{i, x} & \frac{2 N_{i}}{R_{x y}} & 0 & 0 \\
0 & 0 & 0 & N_{i, x} & 0 \\
0 & 0 & 0 & 0 & N_{i, y} \\
0 & 0 & 0 & N_{i, y} & N_{i, x} \\
-\frac{N_{i}}{R_{x}} & -\frac{N_{i}}{R_{X Y}} & N_{i, x} & N_{i} & 0 \\
-\frac{N_{i}}{R_{x y}} & -\frac{N_{i}}{R_{y}} & N_{i, y} & 0 & N_{i}
\end{array}\right]
$$

Where $1 / 2\left(\frac{1}{R_{x}}-\frac{1}{R_{Y}}\right)$ is a term from Sander's theory which accounts for conditions of zero strain for rigid body motion in line with Chandrasekhar [29].

Element elastic bending matrix is given by:

$$
\left[K_{e}\right]=\int_{-1}^{+1} \int_{-1}^{+1}[B]^{T}[D][B]|J| d \xi d \eta
$$

\subsection{Element Geometric Stiffness Matrix Due to Re sidual Stresses $\left[K_{g e}^{r}\right]$}

The non-linear strain equations are represented in matrix form:

$\varepsilon_{n l}=\left\{\varepsilon_{x n l}, \varepsilon_{y n l}, \gamma_{x y n l}\right\}^{T}=[R]\{d\} / 2$

Where

$\{d\}=\left\{u_{x}, u_{y}, v_{x}, v_{y}, w_{x}, w_{y}, \theta_{x, x}, \theta_{x, y}, \theta_{y, x}, \theta_{y, y}, \theta_{x}, \theta_{y}\right\}^{T}$

Equations $\{d\}$ may be expressed as:

$\{d\}=\{G\}\left\{\partial_{e}\right\}$

Where

$[G]=\sum_{i=1}^{8}\left[\begin{array}{ccccc}N_{i, x} & 0 & 0 & 0 & 0 \\ N_{i, y} & 0 & 0 & 0 & 0 \\ 0 & N_{i, x} & 0 & 0 & 0 \\ 0 & N_{i, y} & 0 & 0 & 0 \\ 0 & 0 & N_{i, x} & 0 & 0 \\ 0 & 0 & N_{i, y} & 0 & 0 \\ 0 & 0 & 0 & N_{i, x} & 0 \\ 0 & 0 & 0 & N_{i, y} & 0 \\ 0 & 0 & 0 & 0 & N_{i, x} \\ 0 & 0 & 0 & 0 & N_{i, y} \\ 0 & 0 & 0 & 1 & 0 \\ 0 & 0 & 0 & 0 & 1\end{array}\right]$

The geometric stiffness matrix due to residual stresses is given by:

$$
\left[K^{r}{ }_{g e}\right]=\int_{-1}^{+1} \int_{-1}^{+1}[G]^{T}[S \llbracket G] J \mid d \xi d \eta
$$

Where

$$
[S]=\left[\begin{array}{cccccccccccc}
S_{11} & & & & & & & & & & \\
S_{21} & S_{22} & & & & & & & & & \\
0 & 0 & S_{33} & & & & & & & & \\
0 & 0 & S_{43} & S_{44} & & & & & & & \\
0 & 0 & 0 & 0 & S_{55} & & & & & & \\
0 & 0 & 0 & 0 & S_{65} & S_{66} & & & & & \\
0 & 0 & S_{73} & S_{74} & 0 & 0 & S_{77} & & & & \\
0 & 0 & 0 & S_{83} & S_{84} & 0 & 0 & S_{87} & S_{88} & & & \\
0 & 0 & 0 & 0 & 0 & 0 & S_{99} & & \\
S_{91} & S_{92} & 0 & 0 & 0 & & & \\
S_{101} & S_{102} & 0 & 0 & 0 & 0 & 0 & & S_{109} & S_{110} & & \\
0 & 0 & S_{113} & S_{114} & 0 & 0 & 0 & 0 & 0 & 0 & 0 & \\
S_{121} & S_{122} & 0 & 0 & 0 & 0 & 0 & 0 & 0 & 0 & 0 & 0
\end{array}\right]
$$


In which

$$
\begin{array}{lll}
S_{11}=S_{33}=S_{55}=N^{r}{ }_{x} & S_{22}=S_{44}=S_{66}=N^{r}{ }_{y} & \\
S_{21}=S_{43}=S_{65}=N^{r}{ }_{x y}, & S_{77}=S_{99}=N_{x}{ }^{r} t^{2} / 12, & S_{88}=S_{1010}=N_{y}{ }^{r} t^{2} / 12 \\
S_{87}=S_{109}=N^{r}{ }_{x y} t^{2} / 12, & -S_{73}=S_{91}=M^{r}{ }_{x}, & -S_{84}=S_{102}=M^{r}{ }_{y} \\
-S_{74}=-S_{83}=S_{92}=S_{101}=M^{r}{ }_{x y}, & -S_{113}=S_{121}=Q^{r}{ }_{x}, & -S_{114}=S_{122}=Q^{r}{ }_{y}
\end{array}
$$

\subsection{Geometric Stiffness Matrix Due to Applied} Loads $\left[\begin{array}{ll}K & g e\end{array}\right]$

The first three non-linear strain equations are represented in a matrix form:

$\left\{\varepsilon_{x n l}, \varepsilon_{y n l}, \gamma_{x y n l}\right\}^{T}=[U]\{f\} / 2$

$\{f\}=\left\{u_{x}, u_{y}, v_{x}, v_{y}, w_{x}, w_{y}, \theta_{x, x}, \theta_{x, y}, \theta_{y, x}, \theta_{y, y}\right\}^{T}$

$\{f\}$ is expressed as:

$\{f\}=[H]\left\{\delta_{e}\right\}$

Where

$$
[H]=\sum_{i=1}^{8}\left[\begin{array}{ccccc}
N_{i, x} & 0 & 0 & 0 & 0 \\
N_{i, y} & 0 & 0 & 0 & 0 \\
0 & N_{i, x} & 0 & 0 & 0 \\
0 & N_{i, y} & 0 & 0 & 0 \\
0 & 0 & N_{i, x} & 0 & 0 \\
0 & 0 & N_{i, y} & 0 & 0 \\
0 & 0 & 0 & N_{i, x} & 0 \\
0 & 0 & 0 & N_{i, y} & 0 \\
0 & 0 & 0 & 0 & N_{i, x} \\
0 & 0 & 0 & 0 & N_{i, y}
\end{array}\right]
$$

The geometric stiffness matrix due to applied in-plane loads is given by:

$$
\left[K_{g e}\right]=\int_{-1}^{+1} \int_{-1}^{+1}[H]^{T}[P][H] J \mid d \xi d \eta
$$

Where

$$
[P]=\left[\begin{array}{cccccccccc}
P_{11} & & & & & & & & & \\
P_{21} & P_{22} & & & & & & & & \\
0 & 0 & P_{33} & & & & & & & \\
0 & 0 & 0 & P_{44} & & & & & & \\
0 & 0 & 0 & 0 & P_{55} & & & & & \\
0 & 0 & 0 & 0 & P_{65} & P_{66} & & & & \\
0 & 0 & 0 & 0 & 0 & 0 & P_{77} & & & \\
0 & 0 & 0 & 0 & 0 & 0 & P_{87} & P_{88} & & \\
0 & 0 & 0 & 0 & 0 & 0 & 0 & 0 & P_{99} & \\
0 & 0 & 0 & 0 & 0 & 0 & 0 & 0 & P_{109} & P_{1010}
\end{array}\right]
$$

In which:
$P_{11}=P_{33}=P_{55}=N^{a}{ }_{x}, P_{22}=P_{44}=P_{66}=N^{a}{ }_{y}, P_{21}=P_{43}=P_{65}=N^{a} x y$,

$P_{77}=P_{99}=N^{a}{ }_{x} t^{2} / 12, P_{88}=P_{1010}=N^{a}{ }_{y} t^{2} / 12, \quad P_{87}=P_{109}=N^{a}{ }_{x y} t^{2} / 12$

\subsection{The Element Mass Matrix}

$$
\left[M_{e}\right]=\int_{-1}^{+1} \int_{-1}^{+1}[N]^{T}[P][N] J \mid d \xi d \eta
$$

Where the shape function matrix:

$$
\begin{aligned}
& {[N]=\sum_{i=1}^{8}\left[\begin{array}{ccccc}
N_{i} & 0 & 0 & 0 & 0 \\
0 & N_{i} & 0 & 0 & 0 \\
0 & 0 & N_{i} & 0 & 0 \\
0 & 0 & 0 & N_{i} & 0 \\
0 & 0 & 0 & 0 & N_{i}
\end{array}\right]} \\
& {\left[P_{1}\right]=\left[\begin{array}{ccccc}
P_{1} & 0 & 0 & 0 & 0 \\
0 & P_{1} & 0 & 0 & 0 \\
0 & 0 & P_{1} & 0 & 0 \\
0 & 0 & 0 & I & 0 \\
0 & 0 & 0 & 0 & I
\end{array}\right]}
\end{aligned}
$$

In which the mass moment of inertia

$P_{1}=\sum_{k=1}^{n} \int_{e k-1}^{e k} \rho d z$ and $I=\sum_{K=1}^{n} \int_{e k-1}^{e k} z^{2} \rho d z$

The element load vector due to external transverse static load p per unit area is given by:

$$
\left\{P_{e}\right\}=\iint N_{i}\left[\begin{array}{l}
p \\
0 \\
0
\end{array}\right] d x d y .
$$

\subsection{Load Vector}

The element load vector due to the hygrothermal forces and moments is given by:

$$
\left\{P^{a}\right\}_{e}=\int_{-1}^{+1+1} \int\left[N_{j}\right]^{T}\left\{q^{a}\right\}|J| d \xi d \eta
$$

\subsection{Solution Process}

The element stiffness matrix, the initial stress stiffness matrix due to hygrothermal load, the mass matrix, geometric stiffness matrix due to applied loads and the load vectors of the element are evaluated by first expressing the integrals in local Natural co-ordinates, $\xi$ and $\eta$ of the element and then performing numerical integration by 
using Gaussian quadrature. Then the initial stress resultants $N^{i}{ }_{x}, N_{y}{ }^{i}, N^{i}{ }_{x y}, M^{i}{ }_{x}, M^{i}{ }_{y}, M^{i}{ }_{x y}, Q^{i}{ }_{x}$ and $Q^{i}$ are obtained Next the element matrices are assembled to obtain the respective global matrices $[K],[M],\left[K_{g}^{r}\right],\left[K_{g}\right]$. The next part of the solution involves determination of natural frequencies, buckling load and excitation frequencies from the eigenvalue solutions of the Eq.9 through Eq.11.

\subsection{Computer Program}

A computer program based on the MATLAB environment is developed to perform all necessary computations. The composite panel is divided into a two-dimensional array of rectangular elements. The element elastic stiffness and mass matrices are obtained with $2 \times 2$ gauss points. The geometric stiffness matrix is essentially a function of the in-plane stress distribution in the element due to applied load and residual stress distribution due to hygrothermal load. The overall element stiffness and mass matrices are obtained by assembling the corresponding element matrices using a skyline technique. A reduced integration technique is adopted in order to avoid possible shear locking.

\section{Results and Discussions}

Numerical results are presented on dynamic behavior of laminated composite panels subjected to hygrothermal loading.

\subsection{Boundary Conditions}

The boundary conditions are described as follows:

Simply supported boundary

$\mathrm{S}: \mathrm{u}=\mathrm{v}=\mathrm{w}=\theta y=0$ at $\mathrm{x}=0, \mathrm{a}$, and $\mathrm{u}=\mathrm{v}=\mathrm{w}=\theta x=0$ at $\mathrm{y}=0, \mathrm{~b}$

$\mathrm{S} 2: \mathrm{u}=\mathrm{w}=\theta y=0$ at $\mathrm{x}=0, \mathrm{a}$, and $\mathrm{v}=\mathrm{w}=\theta x=0$ at $\mathrm{y}=0, \mathrm{~b}$

The numerical results are presented for symmetric crossply and anti-symmetric angle-ply laminated composite plates/shells using "S" simply supported conditions, and the comparison with the previous study has been performed for frequency of cross-ply laminated composite shells using the "S2" simply supported conditions used in that study.

The results are grouped as

- Convergence Study

- Comparison with Previous Studies

- Numerical Results

The convergence study is done for non-dimensional frequencies of free vibration of simply supported symmetric cross ply and anti-symmetric angle ply laminated composite plates for elevated temperature and moisture conditions for different mesh divisions as shown in Table 1 and 2.

Table 1. Convergence of non-dimensional free vibration frequencies for SSSS 4 layer panels for different ply orientations at 325K temperature.

$\mathrm{a} / \mathrm{b}=1, \mathrm{a} / \mathrm{t}=100$, At $T=300 \mathrm{~K}, E_{1}=130 \times 10^{9}, E_{2}=9.5 \times 10^{9}, G_{12}=6 \times 10^{9}$
$G_{13}=G_{12}, G_{23}=0.5 G_{12}, v_{12}=0.3, \alpha_{1}=-0.3 \times 10^{-6} /^{0} \mathrm{~K}, \alpha_{2}=28.1 \times 10^{-6} /{ }^{0} \mathrm{~K}$

Non-dimensional frequency, $\lambda=\omega_{n} a^{2} \sqrt{\rho / E_{2} t^{2}}$

\begin{tabular}{ccc}
\hline Mesh & \multicolumn{2}{c}{ Non-dimensional frequencies at $325 K$ Temperature } \\
\cline { 2 - 3 } Division & $(0 / 90 / 90 / 0)$ & $(45 /-45 / 45 /-45)$ \\
\hline $4 \times 4$ & 8.079 & 11.380 \\
$6 \times 6$ & 8.039 & 10.785 \\
$8 \times 8$ & 8.036 & 10.680 \\
$10 \times 10$ & 8.036 & 10.680 \\
& &
\end{tabular}

Table 2. Convergence of non-dimensional free vibration frequencies for SSSS 4 layer panels for different ply orientations at $0.1 \%$ moisture concentration.

$$
\mathrm{l} / \mathrm{b}=1, \mathrm{a} / \mathrm{t}=100, \text { At } C=0.00, E_{1}=130 G p a, E_{2}=9.5 \mathrm{Gpa}, G_{12}=6 \mathrm{Gpa}
$$$$
G_{13}=G_{12}, G_{23}=0.5 G_{12}, v_{12}=0.3, \beta_{1}=0, \beta_{2}=0.44
$$

Non-dimensional frequency, $\lambda=\omega_{n} a^{2} \sqrt{\rho / E_{2} t^{2}}$

\begin{tabular}{ccc}
\hline Mesh & \multicolumn{2}{c}{ Non-dimensional frequencies at $C=0.1 \%$} \\
\cline { 2 - 3 } Division & $(0 / 90 / 90 / 0)$ & $(45 /-45 / 45 /-45)$ \\
\hline $4 \times 4$ & 9.422 & 12.3837 \\
$6 \times 6$ & 9.387 & 11.858 \\
$8 \times 8$ & 9.384 & 11.765 \\
$10 \times 10$ & 9.384 & 11.765 \\
& & \\
\hline
\end{tabular}

The study is further extended to buckling analysis of laminated composite plates subjected to hygrothermal conditions as presented in Table 3 and 4, and this mesh is employed throughout free vibration, buckling and dynamic stability analysis of laminated composite plates in a hygrothermal environment.

Table 3. Convergence of non-dimensional critical load for SSSS 4 layer panels for different ply orientations at $325 \mathrm{~K}$ temperature.

\begin{tabular}{|c|c|c|}
\hline \multicolumn{3}{|c|}{ Non-dimensional critical load, $\lambda={ }^{N_{x c r}} /\left(N_{x c r}\right)_{C=0 \%, T=300 K}$} \\
\hline Mesh & \multicolumn{2}{|c|}{ Non-dimensional critical load at $325 \mathrm{~K}$ Temperature } \\
\hline Division & $(0 / 90 / 90 / 0)$ & $(45 /-45 / 45 /-45)$ \\
\hline $4 \times 4$ & 0.4481 & 0.6120 \\
\hline $6 \times 6$ & 0.4459 & 0.5818 \\
\hline $8 \times 8$ & 0.4457 & 0.5764 \\
\hline $10 \times 10$ & 0.4457 & 0.5764 \\
\hline
\end{tabular}


Table 4. Convergence of non-dimensional critical load for SSSS 4 layer panels for different ply orientations at $0.1 \%$ moisture concentration.

$$
\begin{gathered}
\mathrm{a} / \mathrm{b}=1, \mathrm{a} / \mathrm{t}=100, \operatorname{At} T=300 \mathrm{~K}, E_{1}=130 \mathrm{Gpa}, E_{2}=9.5 \mathrm{Gpa}, G_{12}=6 \mathrm{Gpa} \\
G_{13}=G_{12}, G_{23}=0.5 G_{12}, v_{12}=0.3, \alpha_{1}=-0.3 \times 10^{-6} / /^{0} \mathrm{~K}, \alpha_{2}=28.1 \times 10^{-6} /{ }^{0} \mathrm{~K}
\end{gathered}
$$

Non-dimensional critical load, $\lambda=N_{x c r} /\left(N_{x c r}\right)_{C=0 \%, T=300 \mathrm{~K}}$

\begin{tabular}{ccc}
\hline Mesh & \multicolumn{2}{c}{ Non-dimensional critical load at $\mathrm{C}=0.1 \%$} \\
\cline { 2 - 3 } Division & $(0 / 90 / 90 / 0)$ & $(45 /-45 / 45 /-45)$ \\
\hline $4 \times 4$ & 0.6095 & 0.7255 \\
$6 \times 6$ & 0.6079 & 0.7041 \\
$8 \times 8$ & 0.6078 & 0.7003 \\
$10 \times 10$ & 0.6078 & 0.6990
\end{tabular}

Based on the convergence study, a mesh of $8 \times 8$ is considered for discretization of the panel for all subsequent analysis.

\subsection{Comparison with Previous Studies}

Numerical results are carried out to determine the capability of the present formulation to predict the dynamic behaviour and stability of laminated composite panels.

\subsection{Vibration of Composite Plates And Shells Sub- jected To Hygrothermal Environment}

The present formulation is validated for vibration analysis of composites panels for elevated temperature as shown in Table 5.

Table 5. Comparison of non-dimensional free vibration frequencies for SSSS $(0 / 90 / 90 / 0)$ panels at $325 \mathrm{~K}$ temperature

$$
\begin{gathered}
\mathrm{a} / \mathrm{b}=1, \mathrm{a} / \mathrm{t}=100, \text { At } T=300 \mathrm{~K} \quad E_{1}=130 \mathrm{Gpa}, E_{2}=9.5 \mathrm{Gpa}, G_{12}=6 \mathrm{Gpa} \\
G_{13}=G_{12}, G_{23}=0.5 G_{12}, v_{12}=0.3, \alpha_{1}=-0.3 \times 10^{-6} / /^{0} \mathrm{~K}, \alpha_{2}=28.1 \times 10^{-6} / /^{0} \mathrm{~K}
\end{gathered}
$$

Non-dimensional frequency, $\lambda=\omega_{n} a^{2} \sqrt{\rho / E_{2} t^{2}}$

\begin{tabular}{lcccc}
\hline \multirow{2}{*}{ Methods } & \multicolumn{4}{c}{ Non-dimensional frequencies at 325K Temperature } \\
\cline { 2 - 5 } & 1 & 2 & 3 & 4 \\
\hline Sairam and Sinha [3] & 8.088 & 19.196 & 39.324 & 45.431 \\
& & & & \\
\hline Hung, Hen and Zheng [30] & 8.043 & 18.140 & 38.364 & 44.686 \\
\hline Whitney and Ashton [2] & 8.068 & 18.378 & 38.778 & 44.778 \\
\hline Present FEM & & & & \\
\hline
\end{tabular}

The four lowest non-dimensional frequency parameters due to elevated temperature obtained by the present finite elements are compared with anumerical solution published by Sairam and Sinha [3], Huang et al. [30] using finite element method and Ritz method used by Whitney and Ashton [2].
The non-dimensional frequency parameters for shell with elevated moisture is as shown in Table 6 is compared with results published by Parhi et al. [6] and Naidu and Sinha [10].

Table 6. Comparison of natural frequencies for S2 (0/90/90/0) shell at

\begin{tabular}{|c|c|c|c|c|c|}
\hline $\begin{array}{l}\text { Stacking } \\
\text { sequence }\end{array}$ & source & $\mathrm{C}=0$ & $\mathrm{C}=0.5 \%$ & $\mathrm{C}=1.0 \%$ & $\mathrm{C}=1.5 \%$ \\
\hline $\mathrm{R} / \mathrm{a}=5,(0 / 90)_{2}$ & $\begin{array}{l}\text { Present } \\
\text { Naidu and } \\
\text { Sinha[10] } \\
\text { Parhi } \text { et al. }[6]\end{array}$ & $\begin{array}{l}201.93 \\
201.82 \\
202.02\end{array}$ & $\begin{array}{l}201.78 \\
201.77 \\
201.82\end{array}$ & $\begin{array}{l}201.61 \\
201.68 \\
201.64\end{array}$ & $\begin{array}{l}201.35 \\
- \\
201.44\end{array}$ \\
\hline $\begin{array}{l}\mathrm{R} / \mathrm{a}=10, \\
(0 / 90)_{2}\end{array}$ & $\begin{array}{l}\text { Present } \\
\text { Naidu and } \\
\text { Sinha[10] } \\
\text { Parhi et al. [6] }\end{array}$ & $\begin{array}{l}129.08 \\
129.13 \\
129.20\end{array}$ & $\begin{array}{l}128.34 \\
128.31 \\
128.73\end{array}$ & $\begin{array}{l}128.62 \\
127.54 \\
128.32\end{array}$ & $\begin{array}{l}127.23 \\
- \\
127.87\end{array}$ \\
\hline
\end{tabular}
$1 \%$ moisture concentration

$$
\begin{gathered}
\mathrm{a} / \mathrm{b}=1, \mathrm{a} / \mathrm{t}=100, E_{1}=172.5 G p a, E_{2}=6.9 G p a_{(\mathrm{C}=0)}, G_{12}=3.45 G p a{ }_{, \mathrm{E}_{2}}=6.17 \mathrm{Gpa}(\mathrm{C}=1.0 \%) \\
G_{13}=G_{12}, G_{23}=1.38 G_{12}, v_{12}=0.25, \beta_{1}=0, \beta_{2}=0.44_{, \rho}=1600
\end{gathered}
$$

Fundamental natural frequency, $\lambda=\omega_{n} a^{2} \sqrt{\rho / E_{2} t^{2}}$

The present finite element results show good agreement with the previous numerical results published in the literature for free vibration of laminated composite plates and shells subjected to hygrothermal conditions. The present finite element results are in accordance with the previous analytical as well as computational results of other authors.

\subsection{Buckling of Composite Plates Subjected To Hy- grothermal Environment}

The present formulation is then validated for buckling analysis of laminated composite panels due to hygrothermal loadings with a numerical solution published by Sairam and Sinha [31] and Patel et al. [4] as shown in Table 7.

Table 7. Comparison of non-dimensional critical load for SSSS $(0 / 90 / 90 / 0)$ panels at $325 \mathrm{~K}$ temperature and $0.1 \%$ moisture concentration.

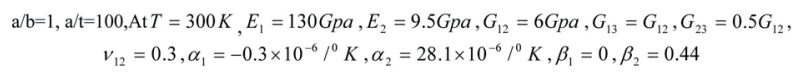

Non-dimensional critical load, $\lambda=N_{x c r} /\left(N_{x c r}\right)_{C=0 \%, T=300 \mathrm{~K}}$

\begin{tabular}{lcc}
\hline \multirow{2}{*}{ Methods } & \multicolumn{2}{c}{ Non-dimensional critical load $\lambda$} \\
\cline { 2 - 3 } & At T=325K & At C=0.1\% \\
\hline Sai Ram and Sinha [31] & 0.4488 & 0.6099 \\
Present FEM & $(0.4481)$ & $(0.6095)$ \\
\hline Patel, Ganapathi and Makhecha [4] & 0.4466 & 0.6084 \\
Present FEM & $(0.4457)$ & $(0.6078)$ \\
\hline
\end{tabular}

The square panel has four layers of Graphite/Epoxy composite. The present finite element results show good accordance with the previous numerical results published in the literature for buckling of composite plates subjected to hygrothermal loads. 


\subsection{Numerical Results For Dynamic Stability Of Shells}

After validating the formulation, the same is employed to study the dynamic stability effects of laminated composite shells in a hygrothermal environment. Numerical results are presented on the dynamic stability of cross-ply and angle-ply laminated shell to study the effects of various parameters on instability regions. The geometrical and material properties of the laminated shell are as follows:

$\mathrm{a}=500 \mathrm{~mm}, \mathrm{~b}=500 \mathrm{~mm}, \mathrm{t}=5 \mathrm{~mm}, \mathrm{E}_{1}=130 \mathrm{Gpa}, \mathrm{E}_{2}=9.5 \mathrm{Gpa}$, $\mathrm{G}_{12}=6 \mathrm{Gpa}, \mathrm{G}_{23} / \mathrm{G}_{12}=0.5, \quad v_{12}=0.3, \quad \mathrm{G}_{13}=\mathrm{G}_{12}, \alpha_{1}=-0.3 \times 10^{-6} / \mathrm{K}$, $\beta_{2}=28.1 \times 10^{-6} / \mathrm{K}$

The non-dimensional excitation frequency $\Omega=\bar{\Omega} \mathrm{a}^{2} \sqrt{(\rho} / E_{22} \mathrm{~h}^{2}$ is used throughout the dynamic instability studies, where $\bar{\Omega}$ is the excitation frequency in radian/sec. The principal instability regions of laminated composite curved panels subjected to in-plane periodic loads is plotted by the non-dimensional frequency $\Omega / \omega$ (ratio of excitation frequency to the free vibration frequency) versus the dynamic in-plane load $\beta$. The analysis is focused on the determination of the primary instability regions of laminated composite shells under hygrothermal loads.

\subsection{Effect of Static Load Factor on Instability Re- gions of Uniformly Loaded Symmetric Shell}

The effect of the static component of load for $\alpha=0.0$, $0.2,0.4,0.6$ and 0.8 on the instability region of laminated composite panels subjected to elevated temperature $325 \mathrm{~K}$ is shown in fig. 5 .

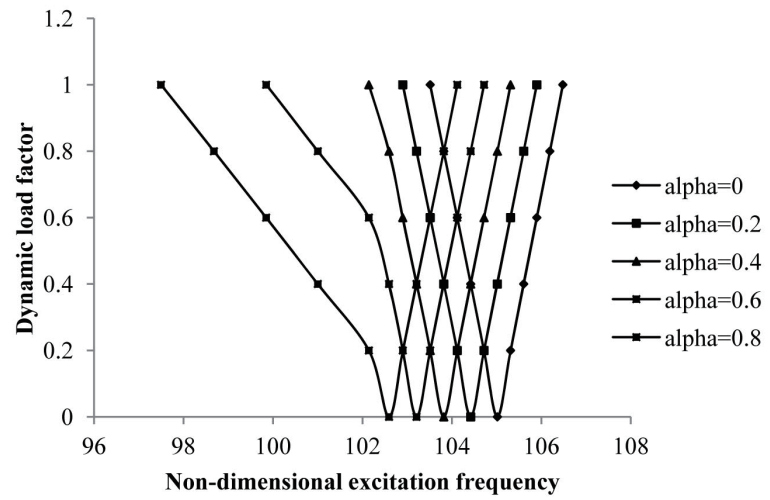

Fig. 5. Variations of instability region with static load factor of composite symmetric laminated shell subjected to elevated temperature ( Temp $=325 K, a / b=1, R y / b=R x / b=5, b / t=100)$

Due to an increase of the static component of the load, the instability regions tend to shift to lower frequencies and become wider. With an increase in the static load factor from 0 to 0.8 , the excitation frequency is reduced by $2.3 \%$. All further studies are made with a static load factor of 0.2 (unless otherwise mentioned).

\subsection{Effects of Temperature on Excitation Frequency}

The variation of excitation frequency with dynamic load factors of composite laminated simply-supported symmetric cross-ply square shells subjected to uniform distribution of temperature from $300 \mathrm{~K}$ and $325 \mathrm{~K}$ is shown in figure 6 .

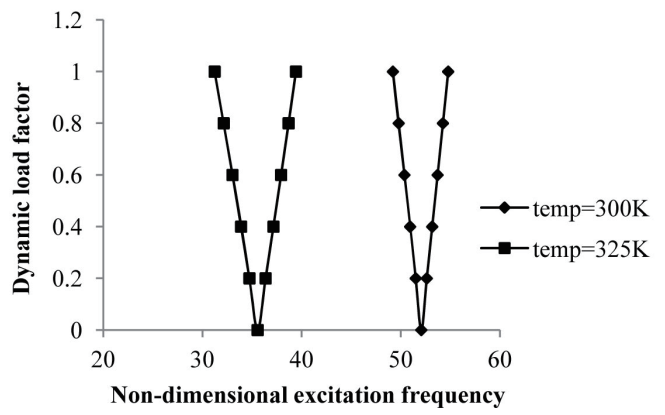

Fig. 6. Variations of instability region with temperature of composite laminated symmetric cross-ply (0/90/90/0) curved panel $(\mathrm{a} / \mathrm{b}=1, \mathrm{~b} /$ $\mathrm{t}=100, \mathrm{Ry} / \mathrm{b}=5$ )

It is observed that the onset of instability occurs earlier with wider DIR for symmetric cross-ply laminated composite panels subjected to elevated temperature compared to composite panels with normal temperature. With an increase in temperature from $300 \mathrm{~K}$ to $325 \mathrm{~K}$, the excitation frequency is reduced by $31.6 \%$. The width of the instability region for laminated panels with elevated temperature is increased by $46.67 \%$ from the plate with normal temperature for a dynamic load factor of 0.6 . The variation of excitation frequency with dynamic load factors of composite laminated simply-supported anti-symmetric angle-ply square shells subjected to uniform distribution of temperature from $300 \mathrm{~K}$, $325 \mathrm{~K}, 350 \mathrm{~K}, 375 \mathrm{~K}$ and $400 \mathrm{~K}$ is shown in figure 7.

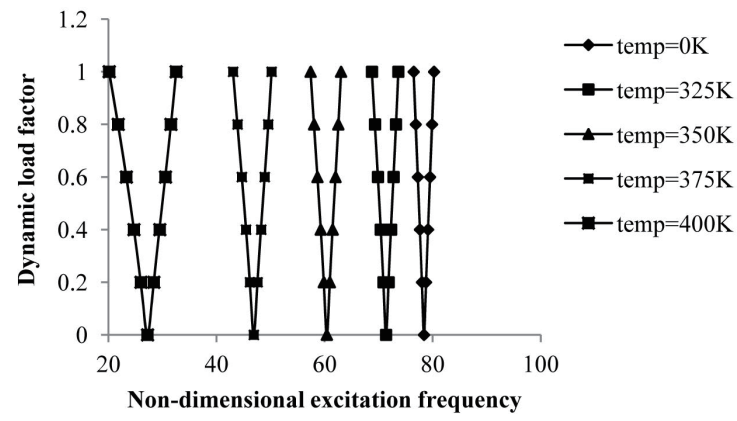

Fig. 7. Variations of instability region with temperature of composite laminated anti-symmetric angle-ply (45/-45/45/-45) curved panel (a/ $b=1, b / t=100, R y / b=5$ ) 
As shown, the onset of instability occurs earlier with wider DIR for anti-symmetric angle-ply laminated composite shells subjected to elevated temperature compared to composite shells with ambient temperature. With an increase in temperature from $300 \mathrm{~K}$ to $350 \mathrm{~K}$, the excitation frequency is reduced by $65.2 \%$.

\subsection{Effects of Moisture on Excitation Frequency:}

The variation of excitation frequency with dynamic load factors of composite laminated simply-supported symmetric cross-ply curved panels subjected to uniform distribution of moisture concentration from $0 \%$ and $0.1 \%$ is shown in fig 8 .

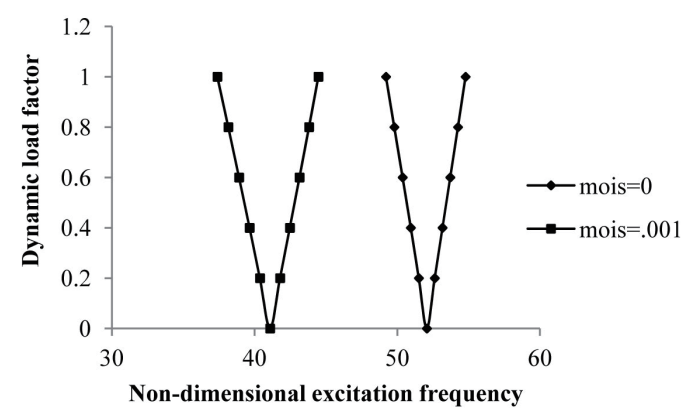

Fig. 8. Variations of instability region with moisture of composite laminated symmetric cross-ply (0/90/90/0) shell $(\mathrm{Ry} / \mathrm{b}=5, \mathrm{a} / \mathrm{b}=1, \mathrm{~b} /$ $\mathrm{t}=100$ )

It is revealed that the onset of instability occurs earlier with wider DIR for symmetric cross-ply laminated composite shells subjected to an elevated moisture condition compared to composite shells with normal moisture. When moisture concentration is increased from $0 \%$ to $0.1 \%$ then excitation frequency reduces by about $21 \%$. The width of the instability region for laminated shells with elevated moisture is increased by $46.67 \%$ from the shell with ambient moisture for a dynamic load factor of 0.6. The variation of excitation

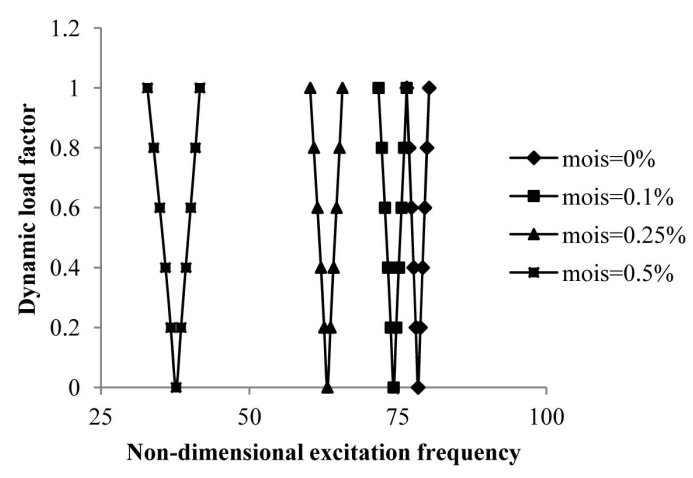

Fig. 9. Variations of instability region with moisture of composite laminated anti-symmetric angle-ply (45/-45/45/-45) shell (Ry/b=5, a/ $b=1, b / t=100$ ) frequency with dynamic load factors of composite laminated simply-supported anti-symmetric angle-ply curved panels subjected to uniform distribution of moisture concentration from $0 \%, 0.1 \%, 0.25 \%$ and $0.5 \%$ is shown in fig 9 .

It is revealed that the onset of instability occurs earlier with wider DIR for anti-symmetric angle-ply laminated composite shells subjected to an elevated moisture condition compared to composite shells with a normal moisture concentration. When moisture concentration is increased from $0 \%$ to $0.25 \%$ then excitation frequency reduces by about $49.3 \%$.

\subsection{Effects of Curvature on Excitation Frequency}

Studies have also been made (Fig 10) for the comparison of instability regions for different shell geometries.

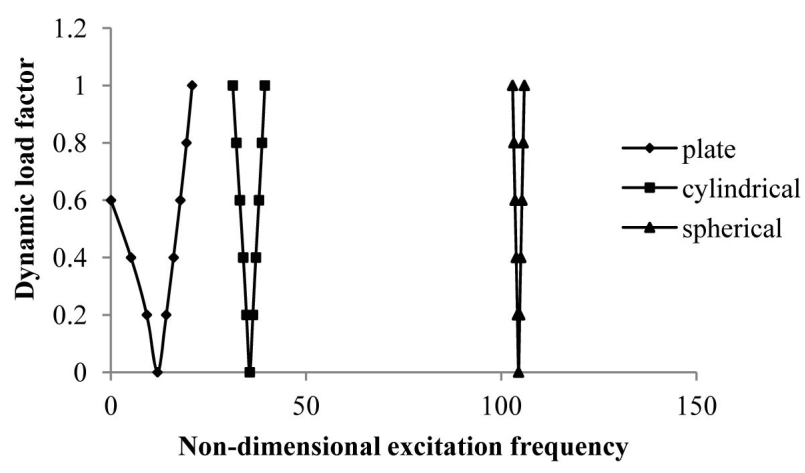

Fig. 10. Variations of curvature of composite laminated symmetric cross-ply $(0 / 90 / 90 / 0)$ curved panel with elevated temperature ( Temp $=325 \mathrm{~K}, \mathrm{a} / \mathrm{b}=1, \mathrm{~b} / \mathrm{t}=100$ )

The effect of curvature on instability regions of different curved panels for $\mathrm{a} / \mathrm{b}=1$, flat panel $\left(\mathrm{a} / \mathrm{R} x=\mathrm{b} / \mathrm{R}_{y}=0\right)$, Cylindrical $\left(\mathrm{a} / \mathrm{R} x=0, \mathrm{~b} / \mathrm{R}_{y}=0.2\right)$ and Spherical $(\mathrm{a} / \mathrm{R} x=\mathrm{b} /$ $\left.\mathrm{R}_{y}=0.2\right)$ is investigated. It is observed that the excitation frequency increases with the introduction of curvatures from flat panels to doubly curved panels in an elevated temperature. The onset of dynamic instability regions occurs earlier with wider dynamic instability regions (DIR) coming from spherical laminated composite shell panels to laminated composite flat panels subjected to uniform distribution of temperature.

\subsection{Effects of Aspect Ratio on Excitation Frequen- cy}

The variation of instability regions with dynamic load factors of composite laminated simply supported symmetric cross-ply and anti-symmetric angle-ply shells with excitation 
frequency subjected to a uniform distribution of elevated temperature with different aspect ratio $(\mathrm{a} / \mathrm{b}=1,2$ and 3$)$ are shown in figures 11 and 12.

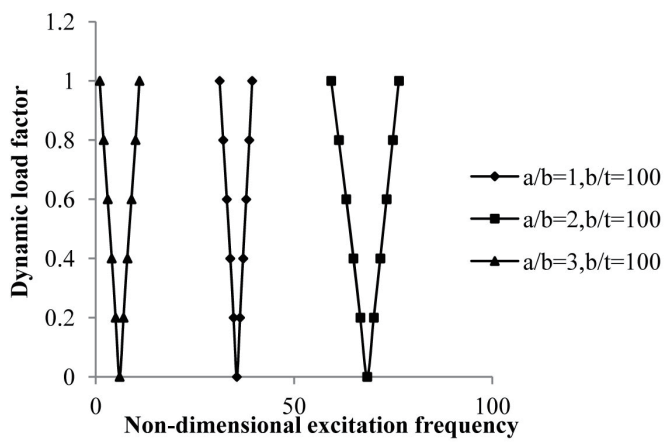

Fig. 11. Effect of aspect ratio on instability region of (0/90/90/0) laminate for elevated temperature $(\mathrm{Ry} / \mathrm{b}=5, \mathrm{Temp}=325 \mathrm{~K}, \mathrm{~b} / \mathrm{t}=100)$

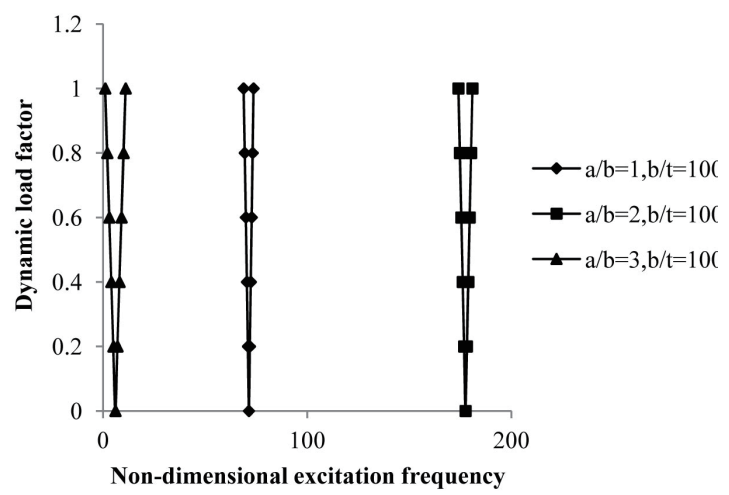

Fig. 12. Effect of aspect ratio on instability region of (45/-45/45/-45) laminate for elevated temperature $(\mathrm{Ry} / \mathrm{b}=5, \mathrm{Temp}=325 \mathrm{~K}, \mathrm{~b} / \mathrm{t}=100)$

It is observed that the onset of instability occurs earlier with a decrease of the aspect ratio with a decreasing width of the instability region. The onset of instability occurs later for rectangular anti-symmetric angle-ply laminated composite shells rather than square shells subjected to elevated temperatures but with wider instability regions. The width of instability regions increased marginally for rectangular plates rather than square plates with a uniform rise in temperature and moisture concentrations. The increase in aspect ratio shifts the frequency of the instability region to higher values and reduces the dynamic stability strength. The variation of the instability region with dynamic load factors of composite laminated simply supported symmetric cross-ply and antisymmetric angle-ply shells with an excitation frequency subjected to uniform distribution of elevated moisture with different aspect ratios $(\mathrm{a} / \mathrm{b}=1,2$ and 3$)$ are shown in figures 13 and 14.

It is observed that the onset of instability occurs earlier

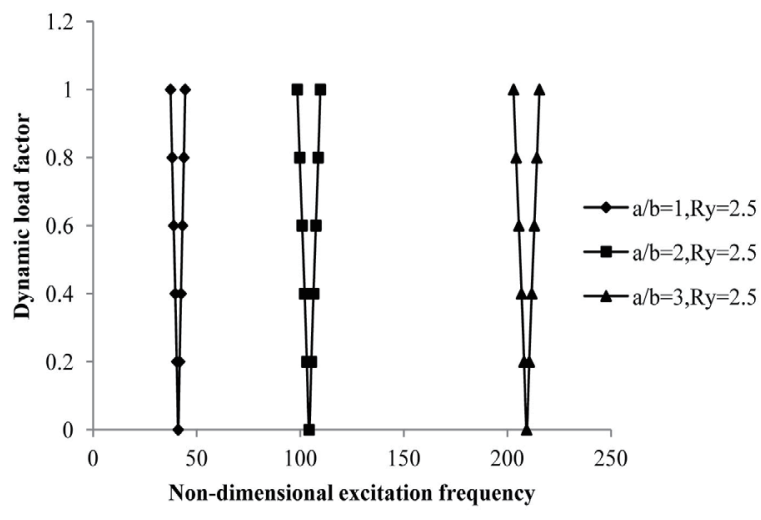

Fig. 13. Effect of aspect ratio on instability region of (0/90/90/0) laminate for elevated moisture $(\mathrm{Ry} / \mathrm{b}=5$, Mois $=0.001, \mathrm{~b} / \mathrm{t}=100)$

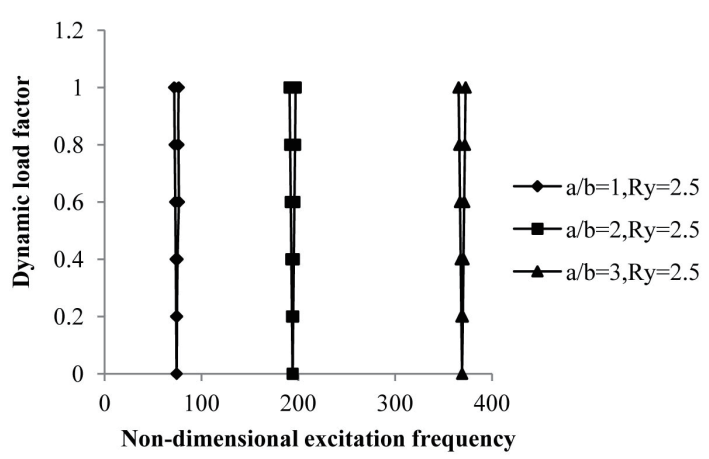

Fig. 14. Effect of aspect ratio on instability region of (45/-45/45/-45) laminate for elevated moisture $(\mathrm{Ry} / \mathrm{b}=5$, Mois $=0.001, \mathrm{~b} / \mathrm{t}=100)$

with a decrease of the aspect ratio with decreasing width of the instability region. The onset of instability occurs later for rectangular anti-symmetric angle-ply laminated composite shells rather than square shells subjected to elevated moisture but with wider instability regions. The width of instability regions increased marginally for rectangular shells rather than square shells with a uniform rise in moisture concentration. The increase in aspect ratio shifts the frequency of instability region to higher values and reduces the dynamic stability strength.

\subsection{Effects on Degree of Orthotropy}

The variation of excitation frequency with dynamic load factors of composite laminated simply supported symmetric cross-ply and for anti-symmetric angle-ply shells subjected to uniform distribution of temperature are shown in figures 15 and 16.

The effect of the degree of orthotropy is studied for $\mathrm{E}_{1} /$ $\mathrm{E}_{2}=40,20,10$ keeping other material properties constant. It is observed that the onset of instability occurs later with an increase of degree of orthotropy for symmetric cross- 


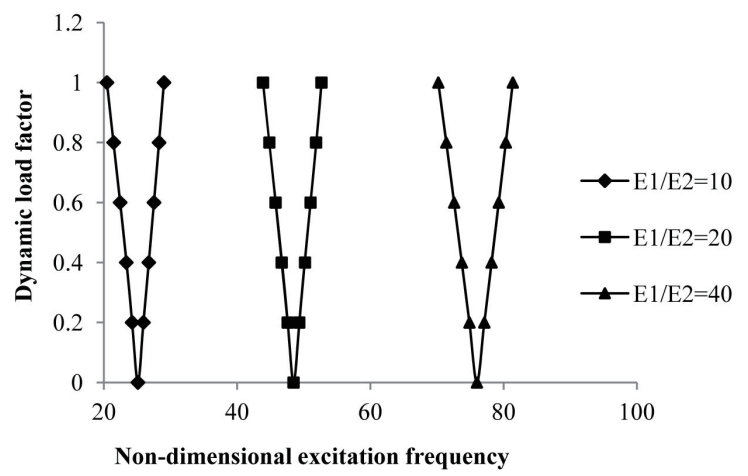

Fig. 15. Effect of degree of orthotropy on instability region of $(0 / 90 / 90 / 0)$ laminate for elevated temperature $(\mathrm{Ry} / \mathrm{b}=5, \mathrm{Temp}=325 \mathrm{~K}$, $\mathrm{b} / \mathrm{t}=100, \mathrm{a} / \mathrm{b}=1$ )

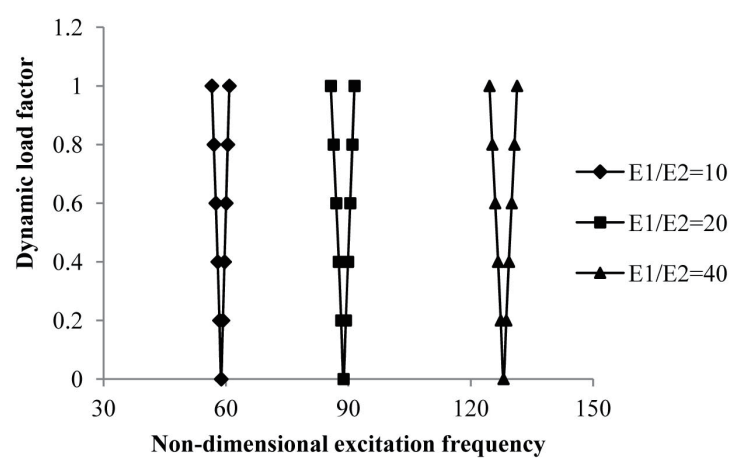

Fig. 16. Effect of degree of orthotropy on instability region of (45/$45 / 45 /-45)$ laminate for elevated temperature $(\mathrm{Ry} / \mathrm{b}=5, \mathrm{Temp}=325 \mathrm{~K}$, $\mathrm{b} / \mathrm{t}=100, \mathrm{a} / \mathrm{b}=1$ )

ply and anti-symmetric angle-ply laminated composite shells subjected to elevated temperature but with wider instability regions. The excitation frequency is reduced but the instability region is wider in cross-ply symmetric laminate rather than anti-symmetric angle-ply laminate. The variation of excitation frequency with dynamic load factors of composite laminated simply supported symmetric cross-ply and for anti-symmetric angle-ply shells subjected to uniform distribution of moisture are shown in figures 17 and 18.

The effect of degree of orthotropy is studied for $\mathrm{E}_{1} / \mathrm{E}_{2}=$ $40,20,10$ keeping other material properties constant. It is observed that the onset of instability occurs later with an increase of degree of orthotropy for symmetric cross-ply and anti-symmetric angle-ply laminated composite shells subjected to uniform distribution of moisture but with wider instability regions. The excitation frequency is reduced but the instability region is wider.

\subsection{Effect of Thickness}

The variation of excitation frequency with dynamic load

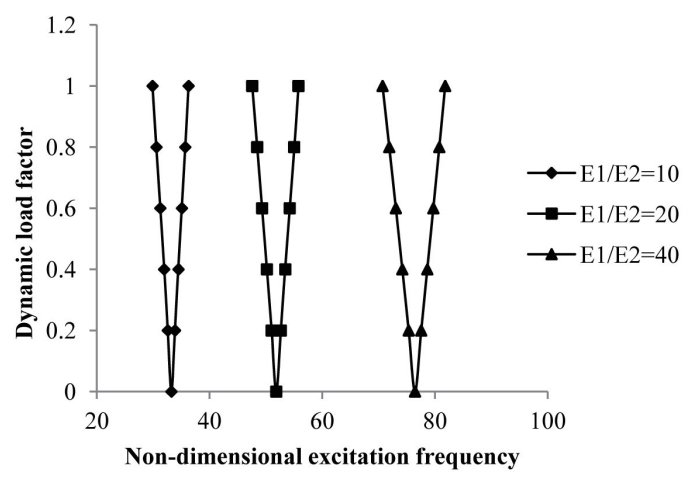

Fig. 17. Effect of degree of orthotropy on instability region of $(0 / 90 / 90 / 0)$ laminate for elevated moisture $(\mathrm{Ry} / \mathrm{b}=5, \mathrm{Mois}=0.001, \mathrm{~b} /$ $t=100, a / b=1$ )

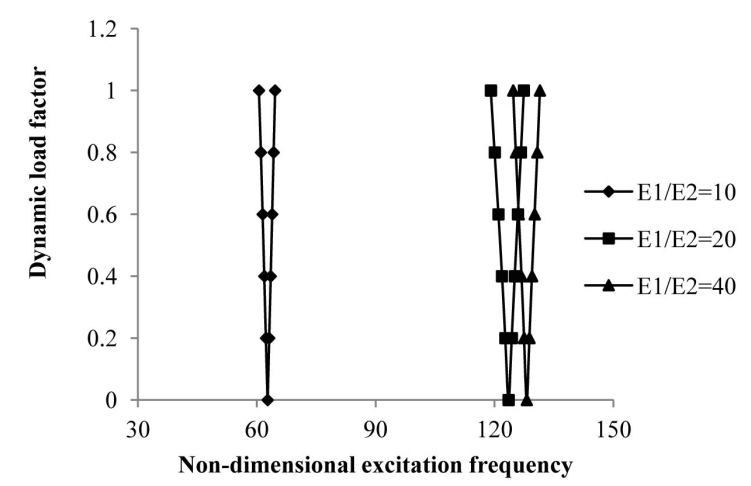

Fig. 18. Effect of degree of orthotropy on instability region of (45/$45 / 45 /-45)$ laminate for elevated moisture $(R y / b=5$, Mois $=0.001$, b/ $\mathrm{t}=100, \mathrm{a} / \mathrm{b}=1$ )

factosr of composite laminated simply supported symmetric cross-ply and for anti-symmetric angle-ply shells subjected to uniform distribution of temperature are shown in figures 19 and 20.

The effect of radius to thickness ratio is studied for $\mathrm{R} x / \mathrm{h}=$ $\mathrm{R}_{y} / \mathrm{h}=625,500,375$ keeping other geometries and material properties constant. It is observed from the figure that the onset of dynamic instability region occurs later with an

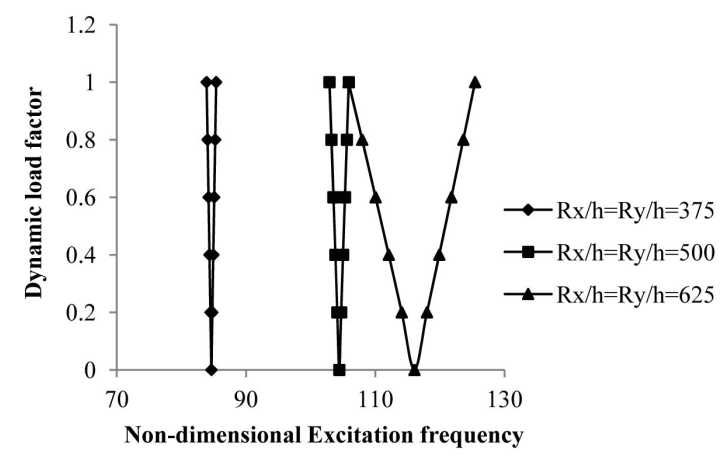

Fig. 19. Effect of thickness on instability region of $(0 / 90 / 90 / 0)$ laminate for elevated temperature $(a / b=1, \operatorname{Temp}=325 \mathrm{~K}, \mathrm{Rx} / \mathrm{b}=\mathrm{Ry} / \mathrm{b}=5)$ 


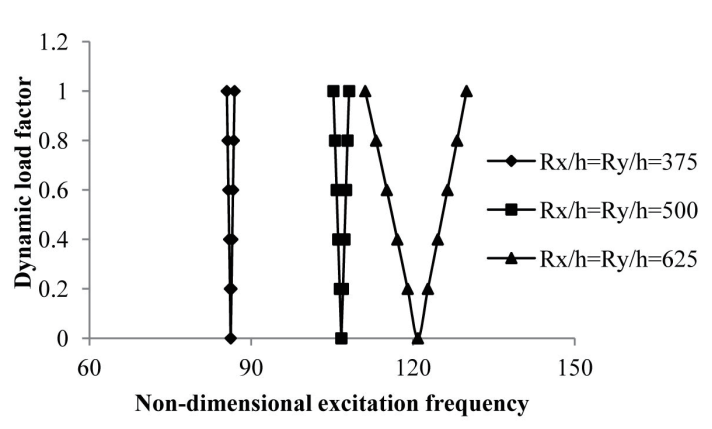

Fig. 20. Effect of thickness on instability region of (45/-45/45/-45) laminate for elevated temperature $(a / b=1, b / t=100, T e m p=325 K, R x /$ $\mathrm{b}=\mathrm{Ry} / \mathrm{b}=5$

increase of $\mathrm{Ry} / \mathrm{h}$ ratio but with wider instability regions. The excitation frequency is reduced but the instability region is narrower in cross-ply symmetric laminate rather than antisymmetric angle-ply laminate in elevated temperatures. The variation of excitation frequency with dynamic load factors of composite laminated simply supported symmetric crossply and for anti-symmetric angle-ply shells subjected to uniform distribution of moisture are shown in figures 21 and 22.

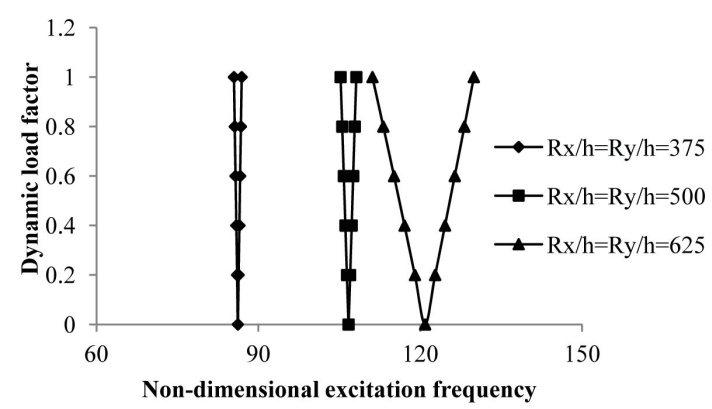

Fig. 21. Effect of thickness on instability region of $(0 / 90 / 90 / 0)$ laminate for elevated moisture $(a / b=1, b / t=100$, Mois $=0.001, R x / b=R y / b=5)$

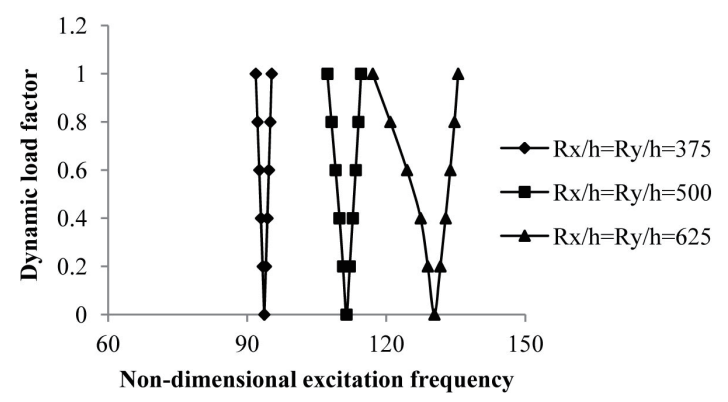

Fig. 22. Effect of thickness on instability region of (45/-45/45/-45) laminate for elevated moisture $(a / b=1, b / t=100$, Mois $=0.001, R x / b=$ $\mathrm{Ry} / \mathrm{b}=5$ )

It is observed from the figure that the onset of dynamic instability region occurs earlier with a decrease of the $\mathrm{Ry} / \mathrm{h}$ ratio but with a narrower instability region. The excitation frequency is reduced but the instability region is narrower in cross-ply symmetric laminate rather than anti-symmetric angle-ply laminate in elevated moisture.

\subsection{Effect of Shallowness Ratio}

The variation of excitation frequency with dynamic load factors of composite laminated simply supported symmetric cross-ply and for anti-symmetric angle-ply shells subjected to uniform distribution of temperature are shown in figures 23 and 24.

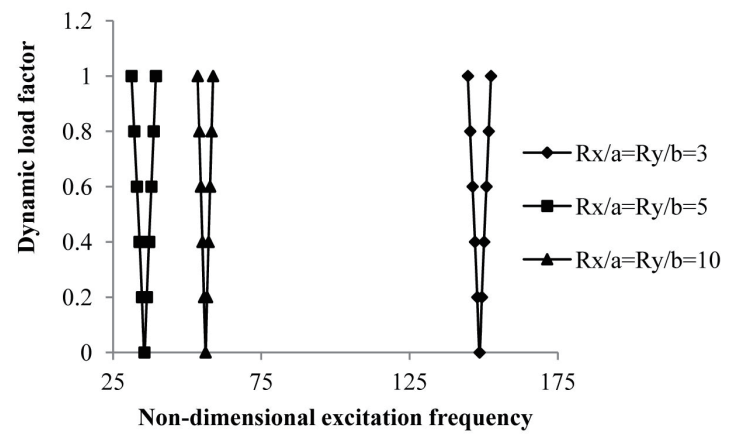

Fig. 23. Effect of Ry/b on instability region of (0/90/90/0) laminate for elevated temperature $(a / b=1, b / t=100, T e m p=325 K, R y=R x=1.5,2.5,5)$

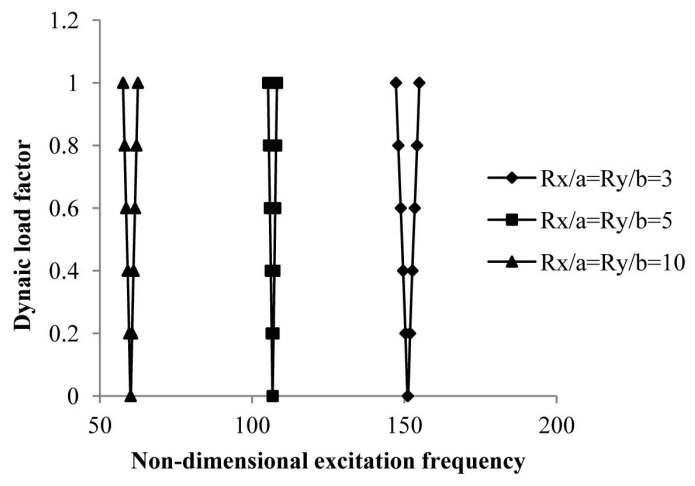

Fig. 24. Effect of Ry/b on instability region of (0/90/90/0) laminate for elevated moisture $(a / b=1, b / t=100$, Mois $=0.001, R y=R x=1.5,2.5,5)$

The effect of the shallowness ratio on instability regions is studied for $\mathrm{R} x / \mathrm{a}=\mathrm{R}_{y} / \mathrm{b}=3,5,10$ keeping other geometries and material properties constant. As seen from the figure, the instability excitation frequency is higher for a decrease of shallowness by decreasing $\mathrm{R}_{x}$ and $\mathrm{R}_{y}$. The onset of instability occurs earlier with an increase of the shallowness ratio but with a wide instability region. The excitation frequency is reduced but the instability region is wider in cross-ply symmetric laminate rather than anti-symmetric angleply laminate in elevated temperatures. The variation of excitation frequency with dynamic load factors of composite laminated simply supported symmetric cross-ply and for anti-symmetric angle-ply shells subjected to are uniform 
distribution of moisture are shown in figures 25 and 26.

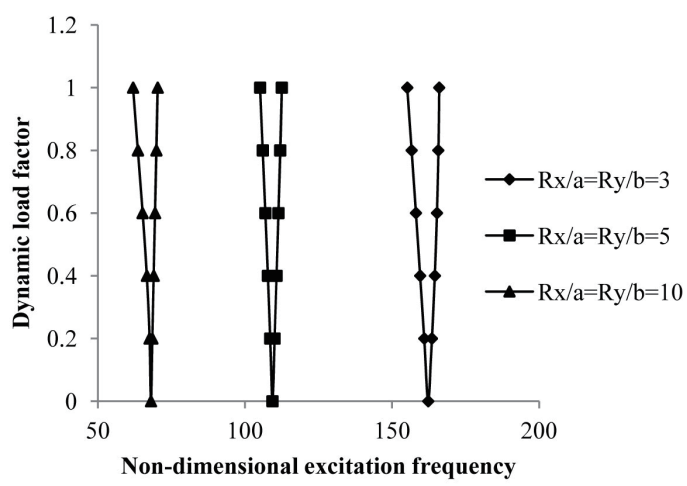

Fig. 25. Effect of Ry/b on instability region of (45/-45/45/-45) laminate for elevated temperature $(a / b=1, b / t=100, T e m p=325 K, R y=R x=1.5$, $2.5,5)$

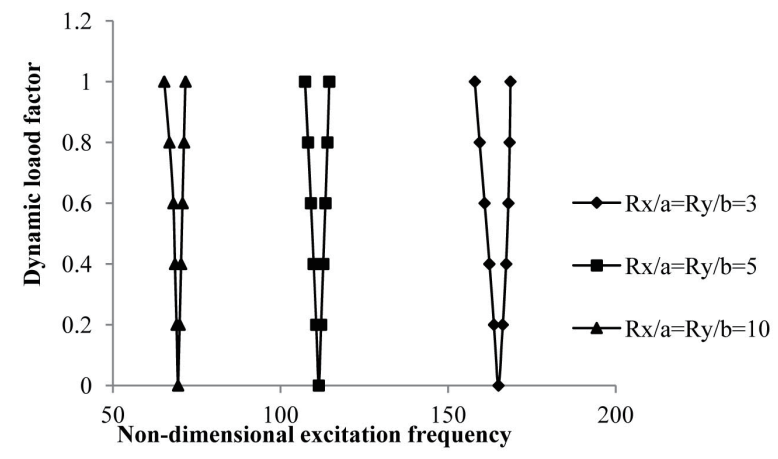

Fig. 26. Effect of Ry/b on instability region of (45/-45/45/-45) laminate for elevated moisture $(a / b=1, b / t=100$, Mois $=0.001, R y=R x=1.5,2.5,5)$

The effect of the shallowness ratio on instability regions is studied for $\mathrm{R}_{x} / \mathrm{a}=\mathrm{R}_{y} / \mathrm{b}=3,5,10$ keeping other geometries and material properties constant. As seen from the figure, the excitation frequency is higher for a decrease of shallowness by decreasing $\mathrm{R} x$ and $\mathrm{R} y$. The onset of instability occurs earlier with an increase of shallowness ratio but with a wide instability region. The excitation frequency is reduced but the instability region is wider in cross-ply symmetric laminate rather than anti-symmetric angle-ply laminate in an elevated moisture.

\subsection{Effect of Ply-Orientation}

The variation of instability regions with dynamic load factors of composite laminated simply supported antisymmetric angle-ply shells with excitation frequency subjected to uniform distribution of temperature with different ply orientations is shown in fig 27.

It is observed that the onset of instability occurs earlier for anti-symmetric angle-ply composite shells with 0 degree

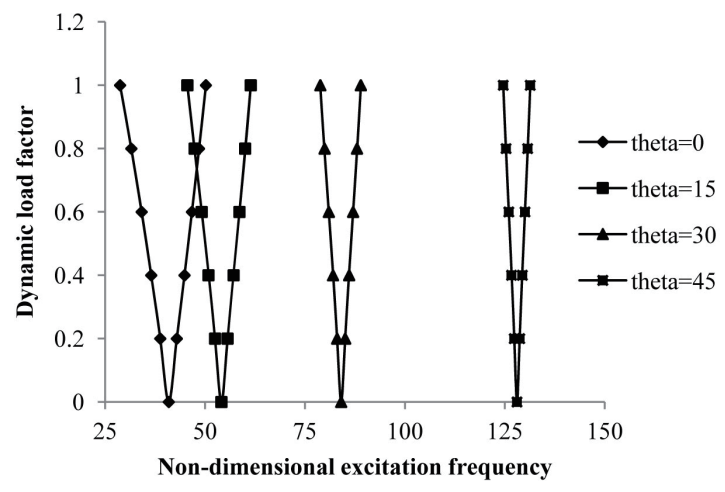

Fig. 27. Effect of different ply orientation on instability region of antisymmetric angle-ply laminate for elevated temperature $(a / b=1, b /$ $\mathrm{t}=100$, Temp $=325 \mathrm{~K}, \mathrm{Ry} / \mathrm{b}=5$ )

of ply orientation than for shells with a higher degree of ply orientation subjected to elevated moisture conditions but with narrow DIR. The value of ply orientation for which the instability region is narrower is 45 and for the wider DIR the ply orientation value is 0 . The instability region is less wide for increase in lamination angle but the excitation frequencies are decreased with a decrease in uniform temperature distribution. The ply orientation for 00 seems to be the preferential ply orientation for this lamination sequence. The variation of instability regions with dynamic load factors of composite laminated simply supported anti-symmetric angle-ply shells with excitation frequency subjected to uniform distributions of moisture with different plv orientations is shown in figure 28.

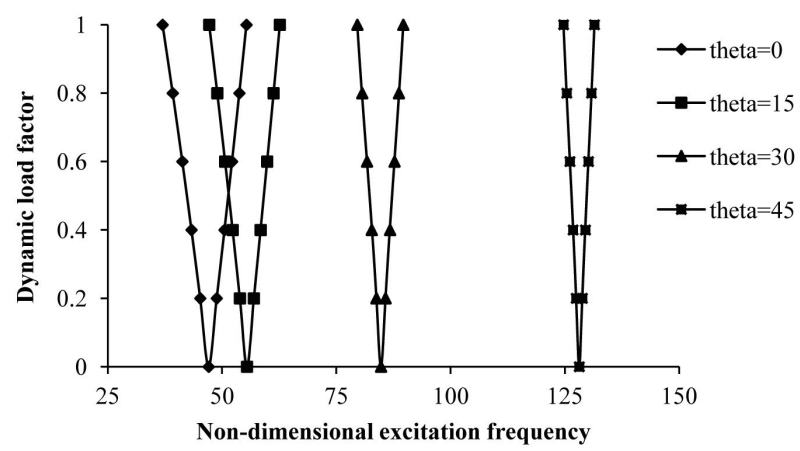

Fig. 28. Effect of different ply orientation on instability region of antisymmetric angle-ply laminate for elevated moisture $(a / b=1, b /$ $\mathrm{t}=100$, Mois $=0.001, \mathrm{Ry} / \mathrm{b}=5$ )

It is observed that the onset of instability occurs earlier for anti-symmetric angle-ply laminated composite shells with 0 degree of ply orientation than the shells with a higher degree of ply orientation subjected to elevated moisture conditions but with narrow DIR. The value of the ply orientation for which the instability region is narrower is 45 and for the 
wider DIR the ply orientation value is 0 . The instability region is less wide for increases in lamination angle but the excitation frequencies are decreased with a decrease in uniform moisture concentration.

\section{Conclusions}

A general formulation for vibration, buckling and parametric resonance characteristics of laminated composite curved panels subjected to in-plane periodic load under hygrothermal environment is presented:

- The excitation frequencies of laminated composite panels decrease with an increase of temperature due to reduction of stiffness for all laminates.

- The excitation frequencies of laminated composite panels also decrease substantially with an increase of moisture concentration for all laminates.

- Due to the static component of loads, the onset of instability shifts to lower frequencies with wide instability regions of the laminated composite panels.

- The instability region is observed to be influenced by the lamination angle of the laminated composite curved panel under hygrothermal loads.

- Increasing the aspect ratio shifts the frequencies of instability regions to higher values and reduces the dynamic stability strength of the laminated composite panel.

- The width of dynamic instability regions is smaller for square laminated composite panels than rectangular panels with hygrothermal load.

- The excitation frequency increases with the introduction of curvatures from flat panel to doubly curved panel in hygrothermal environment.

From the present studies, it is concluded that the instability behavior of laminate composite plates and shells is greatly influenced by the geometry, lamination parameters and hygrothermal conditions. Therefore the designer has to be cautious while dealing with structures subjected to hygrothermal loading. This can be utilized to the designer's advantage during the design of woven fiber laminated composite structures in a hygrothermal environment.

\section{Acknowledgement}

The authors are thankful to Department of Science and Technology, Government of India for their support under the SERC scheme.

\section{References}

[1] Tauchart, T.R., "Thermally induced flexure, buckling, and vibration of plates", Applied Mechanics Review, Vol. 44, No. 8, 1991, pp. 347-360.

[2] Whitney, J.M, and Ashton, J. E., "Effect of environment on the elastic response of layered composite plates", AIAA Journal, Vol. 9, 1971, pp. 1708-13.

[3] Sai Ram, K.S, and Sinha, P.K., "Hygrothermal effects on the free vibration of laminated composite plates", Journal of Sound and Vibration, Vol. 158, No 1, 1992, pp. 133-148.

[4] Patel, B.P. Ganapathi, M., and Makhecha, D. P., "Hygrothermal Effect on the Structural Behavior of Thick Composite Laminates using Higher- order Theory", Composite Structures, Vol. 56, 2002, pp. 25-34.

[5] Librescu, L., and Lin, W., "Vibration of geometrically imperfect panels subjected to thermal and mechanical loads", Journal of Spacecraft and Rockets, Vol.33, No.2, 1996, pp. 285-291.

[6] Parhi, P.K., Bhattacharyya, S.K., and Sinha, P.K., "Hygrothermal effects on the dynamic behavior of multiple delaminated composite plates and shells", Journal of Sound and Vibration, Vol. 248, No.2, 2001, pp. 195-214.

[7] Ganapathi, M, Patel, B.P., and Pawargi, D.S., "Dynamic analysis of laminated cross- ply composite non-circular thick cylindrical shells using higher-order theory", International Journal of Solids and Structures, Vol. 39, 2002, pp. 5945-5962.

[8] Huang, N.N., and Tauchert, T.R., "Large deformations of laminated cylindrical and doubly curved panels under thermal loading", Computers and Structures, Vol. 41, No. 2, 1991, pp.303-312.

[9] Marques, S.P.C., and Creus, G.J., "Geometrically nonlinear finite element analysis of viscoelastic composite materials under mechanical and hygrothermal loads", Computers and Structures, Vol. 53, No. 2, 1994, pp. 449-456.

[10] Swamy Naidu, N.V., and Sinha, P.K., "Nonlinear free vibration of laminated Composite Shells in Hygrothermal condition", Composite Structures, Vol. 77, 2006, pp. 475-483.

[11] Ribeiro, P., and. Jansen, E., "Non-linear vibrations of laminated cylindrical shallow shells Under thermomechanical loading", Journal of Sound and Vibration, Vol. 315, 2008, pp. 626-640.

[12] Kundu, C.K., and Han, J.H., "Vibration characteristics and snapping behavior of Hygro- Thermo-elastic composite doubly curved shells", Composite Structures, Vol. 91, 2009, pp. 306-317.

[13] Panda, S.K., and Singh, B.N., "Large amplitude free vibration analysis of thermally post-buckled composite doubly curved panel using non-linear FEM", Finite Elements in Analysis and Design, Vol.47, 2011, pp. 378-386. 
[14] Lee, S.Y., and Yen, W.J., "Hygrothermal effects on the stability of cylindrical composite shell panel", Computers and Structures, Vol. 33, No.2, 1989, pp. 551-559.

[15] Shen, S.H., "The effects of hygrothermal conditions on the post-buckling of shear deformable laminated cylindrical shells", International Journal of Solids and Structures, Vol. 38, 2001, pp. 6357-6380.

[16] Kundu, C.K., and Han, J.-H., "Nonlinear buckling analysis of hygrothermoelastic composite shell panels using finite element method", Composites Part. B, Vol. 40, 2009, pp.313- 328.

[17] Lal, A., Singh, B.N., and Kale, S., "Stochastic post buckling analysis of laminated composite cylindrical shell panel subjected to hygrothermomechanical loading", Composite Structures, Vol. 93, 2011, pp.1187-1200.

[18] Bolotin, V.V., The Dynamic Stability of Elastic Systems, Holden-Day, San Francisco, United States, 1964.

[19] Nagai, K., and Yamaki, N., "Dynamic stability of circular cylindrical shells", Acta Mechanica, Vol. 71, 1988, pp. 61-76.

[20] Bert, C.W., and Birman, V., "Parametric instability of thick, orthotropic, circular cylindrical shells", Acta Mechanica, Vol.71, 1988, pp.61-76.

[21] Liao, C.L., and Cheng, C.R., "Dynamic stability of stiffened laminated composite plates and shells subjected to in-plane pulsating forces", Journal of Sound and Vibration, Vol.174, No.3, 1994, pp.335-351.

[22] Argento, A., and Scott, R. A., "Dyamic instability of laminated anisotropic circularcylindrical shells part II numerical results", Journal of Sound and Vibration, Vol.162, No.2 1992, pp.323-332.

[23] Ganapati, M., Patel, B. P., Boisse, P., and Touratier M., "Nonlinear dynamic stability Characteristics of elastic plates subjected to periodic in-plane load", International Journal of Non-Linear Mechanics, Vol. 35, 2000, pp. 467-480.
[24] Sahu, S.K., and Datta, P.K., "Parametric resonance characteristics of laminated Composite doubly curved shells subjected to non uniform loading", Journal of Reinforced Plastics and Composites, Vol. 20, No.18, 2001, pp. 1556-1576.

[25] Ng, T.Y., and Lam, K.Y, and Reddy, J.N., "Dynamic stability of cross-ply laminated Composite cylindrical shells", International Journal of Mechanical Sciences, Vol. 40, No.8, 1998, pp.805-823.

[26] Sahu, S.K., and Datta, P.K., "Dynamic stability behaviour of laminated composite curved panel with cutout", Journal of Engineering Mechanics, (ASCE), Vol.129, 2003, pp. 1231-1245.

[27] Liew, K.M., Hu, Y.G., Zhao, X., and, Ng T.Y., “Dynamic stability analysis of Composite laminated Cylindrical Shells via the mesh-free kp-Ritz method", Computer Methods in Applied Mechanics and Engineering, Vol. 196, 2006, pp.147160.

[28] Sahu, S.K., and Asha, A.V, "Parametric resonance characteristics of angle ply twisted curved Panels", International Journal of Structural Stability and Dynamics, Vol. 8, 2008, pp. 61-76.

[29] Cook, R. D., Malkus D.S. and Plesha M. E. Concepts and Applications of Finite Element Analysis, John Wiley, New York, United States, 1989.

[30] Chandrasekhar, K., "Free vibration of anisotropic laminated doubly curved shells", Computers and Structures, Vol. 33, No. 2, 1989, pp.435-440.

[31] Huang, X.L., Shen, H.S., and Zheng, J.J., "Nonlinear vibration and dynamic response of simply supported shear deformable laminated plates in hygrothermal environments", Composite Science and Technology, Vol. 64, 2004, pp. 14191435.

[32] Sai Ram, K.S., and Sinha, P.K., "Hygrothermal effects on the buckling of laminated composite plates", Composite Structures, Vol. 21, 1992, pp. 233-247. 